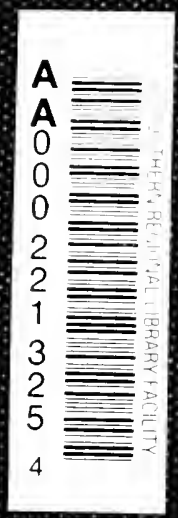




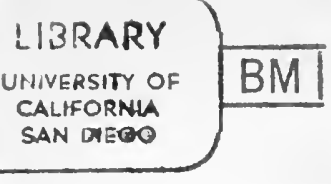

\section{BIOMEDICAL LIBRARY \\ UUUYERSITY OF CALIFORNIA, SAN DIEEO LA JOUA CALFORNIA}

BIOMEUICAL LIBRARY

W MVERSIT DATE DUE

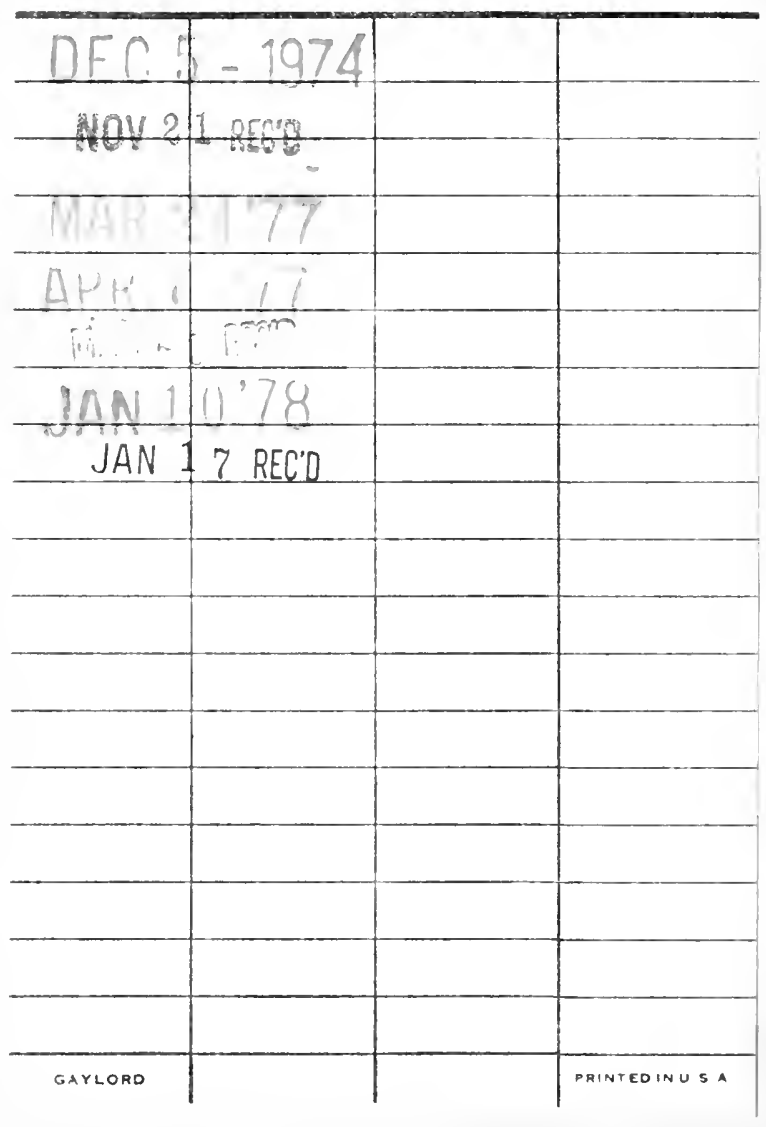




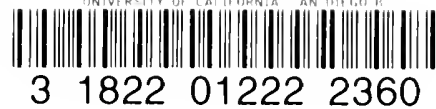

WO
$=2-$
$5+570$
$1-1119$

BM 

Digitized by the Internet Archive in 2008 with funding from

Microsoft Corporation

http://www.archive.org/details/principlesofacid00sell 



\title{
THE PRINCIPLES OF ACIDOSIS AND CLINICAL METHODS FOR ITS STUDY
}

\author{
BY \\ ANDREW WATSON SELLARDS \\ ASSOCIATE IN HARVARD MEDICAL SCHOOL \\ DEPARTMENT OF TROPICAL MEDICINE
}

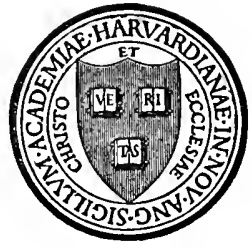

CAMBRIDGE

HARVARD UNIVERSITY PRESS

1919 
COPYRIGHT, 1917

IIARVARD UNIVERSITY PRESS

Issued September 1917

Reprinted July 1919 


\section{PREFATORY NOTE}

Tue development of the theory of acidosis has been a gradual and complicated process. Now that the subject is beginning to take definite form, it has seemed advisable to analyze the more important and representative articles. 'Two excellent reviews of acidosis have appeared in the past, one by Kraus and Honigmann * in 1895 and another by Ewing $\dagger$ in 1908. Since this time fundamental advances have been made.

My own interest in the subject dates from the study in Manila at the Philippine Bureau of Science of acidosis in the nephritis of Asiatic cholera. This was followed by an investigation, along similar lines, of various nephropathies in the elinic of Professor Lewellys F. Barker in Baltimore. The interest in the results has been considerably enhanced by combining the study of the subject in tropical and general medicine; unfortunately these two phases of internal medicine often tend to develop along separate and independent lines.

In order to limit the size of this volume, complete evidence is not quoted for the statements and conclusions which appear, but full references are given in each instance to the literature. In its present form this monograph is intended to cover the requirements for the routine of the clinic as far as theory, application and technical methods are concerned. The classical arrangement as regards the expected sequence of definition,

* Kraus u. Honigmann. Ergeb. d. allgem. Path. Morph. u. Physiol. d. Menschen u. d. Tiere, 1895.

$\dagger$ Ewing. Arch. Int. Med. 1908, II, 330 and 448. 
etiology, diagnosis, and therapy has been sacrificed completely for the sake of simplicity of presentation.

I have endeavored to condense the subject as fully as is consistent with a comprehensive presentation and without neglecting to point out, sometimes in detail, the places where our information is incomplete. The apparently unavoidable length is a source of much regret to me.

I take this occasion to express my indebtedness to Dr. Richard P. Strong, Director of the Harvard School of Tropical Medicine. It also gives me much pleasure to acknowledge the very helpful assistance of Dr. David L. Edsall, Dr. Otto Folin, Dr. Thomas R. Boggs, and Dr. Francis Peabody.

To Miss Catherine M. Casassa, the Secretary of this School, I wish to make grateful acknowledgment for her efficient and conscientious care of the manuscript.

Boston, Massachusetts,

May, 1917. 


\section{CON'TEN'TS}

I. InTroduction + Distinction between titration values and physicochemical reaction. Dissociation and association. Absence of acid properties in dry sulphuric acid.

II. Equilibrium between Acids and Bases . . . . Methods of disposing of the excess of the acid end-products of a normal diet. Oxidation and excretion. Henderson's factor: nentrality regulation by the phosphates, carbonates and proteins of the serum. Interception of ammonia. Quantitative increase of these processes in acidosis. Importance of fixed bases for the internal respiration. The hypothetical condition of alkalosis.

III. Methiods of Diagnosing Acidosis . . . . . . . . Clinical Signs. Laboratory methods. Constancy of physicochemical reaction of blood in acidosis. Confusion concerning the reaction of the blood in pregnancy. Behavior of carbon dioxide and ammonia. Desirability of a delicate and pathognomonic test of general application.

IV. Behavior of the Body in Health and in Acidosis TOWARDs Sodium Bicarbonate . . . . . . . . The testing of the tolerance to bicarbonate. Occurrence of high tolerance in various nephropathies. Interpretation of this tolerance. Proof that it represents an acidosis.

V. Relative Value of the Various Tests for Acidosis . Relative delicacy of the various tests. Precautions to be observed in interpretation of acetone, carbon dioxide and ammonia. Choice of tests under various conditions; the tests employed in establishing the occurrence of acidosis in certain nephropathies.

VI. Definition of Acidosis

An impoverishment of the body in fixed bases. Fallacy of dividing acidoses into relative and absolute types and difficulty of distinguishing compensated and uncompensated cases. Selection of a standard test for detecting systemic changes in the alkali reserve. 
VII. Occurrence of Acidosis .

Fatal forms in diabetes in certain nephropathies and some of the diseases of children. Moderate grades of acidosis in other conditions. Tendency to exaggerate the frequency of acidosis.

VIII. THERAPY

Mode of action of alkalies. Beneficial action in acute nephritis of Asiatic cholera. Consideration of chronic nephritis. Lack of permanent value of alkali therapy in advanced acidoses and some possible explanations.

IX. Differential Diagnosis . . . . . . . . . . . . . Differentiation of the various comas. Constancy of acidosis in uraemia as contrasted with cardiac and cerebral conditions.

X. Etiology of Acidosis .............. . .

Disturbance of oxidation in diabetes and impaired elimination in nephritis. Fundamental and incidental features of acidosis. Incomplete knowledge in regard to the ammonia metabolism. Evidence that acidosis in nephritis is a secondary and not a primary factor.

XI. Résumé . . . . . . . . . . . . . . 83

XII. Appendix. Technique of Methods . . . . . . . 95

BIBLIOGRAPHY . . . . . . . . . . . . 112 


\section{THE PRINCIPLES OF ACIDOSIS AND CLINICAL METHODS FOR ITS STUDY}





\section{IN'TRODUCTION}

Tue phenomenon of acidosis apparently represents one of the simpler problems in biological chemistry; nevertheless the development of the subject has been very gradual although it has occupied a prominent place in the field of internal medicine for several decades. Numerous erroneous conceptions have arisen from time to time and these are being eliminated only with difficulty.

The theory had its inception in 1850 when Boussingault ${ }^{1}$ using very satisfactory methods made the extremely valuable discovery that large amounts of ammonia frequently appear in the urine of diabetic patients. As pointed out by Folin ${ }^{2}$ it was not until 1880 that Hallervorden ${ }^{3}$ using an inferior technique repeated and confirmed Boussingault's work. Notwithstanding these circumstances the work is usually attributed to Hallervorden. The search for acid radicals to account for the presence of these ammonium salts in acid urine culminated in 1883 in Stadelmann's ${ }^{4}$ discovery of oxybutyric acirl. Confusing theories were arising at this period but already in 1877 Walter ${ }^{5}$ had clarified the situation considerably by demonstrating in animals that the ingestion of mineral acids proved fatal although the blood serum remained faintly alkaline to litmus. The first definite clinical observations were made during this period by Kussmaul ${ }^{6}$ who noted the air hunger of advanced diabetic patients. In recent years there has been renewed activity in the study of acidosis, particn- 
larly of those types of non-diabetic origin. These investigations have served to emphasize that the fixed alkalies are necessary for the physiological requirements of the body and that they are essential to life.

In considering the requisite constituents of a balanced diet attention is not ordinarily directed toward the alkalies since this component usually regulates itself automatically. However, it is only by careful regulation and conservation that a sufficient supply is maintained in the body to meet the normal physiological requirements of metabolism. With an ordinary mixed diet there is a tendency toward a constant production of acid radicals, but these radicals are prevented from appearing as free acid in the blood or other tissues chiefly by two processes, namely, excretion and neutralization. In an exactly similar manner, i. e., by excretion and neutralization, the body also provides against the accumulation of excessive amounts of alkali. Upon closer examination it will be seen that, by means of a delicately balanced mechanism, the equilibrium between acids and bases is maintained at a remarkably constant level. The maintenance of this equilibrium is of fundamental importance inasmuch as a nice adjustment of the reaction of the various fluids and tissues is important for many of the processes taking place in the body. Henderson ${ }^{7}$ has emphasized that the constancy of the reaction of the blood is even more carefully guarded than the other great constants of the body such as temperature and osmotic pressure.

Before discussing the mechanism by which this equilibrium is controlled, it will be well to review briefly a few preliminary considerations regarding acids and bases and the reactions of solutions. In the first place, 
one must not lose sight of the fact that many neutral or practically neutral substances may be capable of maintaining their neutrality even after the addition of free acid or base; consequently one does not require even a weak base to neutralize a strong acid. One of the simplest examples of this is the neutralization of hydrochloric acid by a suspension of neutral calcium carbonate. A more interesting illustration is afforded by blood serum, which, though only very slightly alkaline can, by virtue of its carbonates, phosphates and proteins, neutralize moderate amounts of acid. This ability to neutralize acid or base may conveniently be termed "titratable reaction" in distinction from the actual reaction. The true reaction of a fluid concerns itself only with that portion of acid or base which, after going into solution, becomes dissociated into hydrogen and hydroxyl ions. The absolute dependence of the reaction upon the splitting up of an acid or alkali into its ions may be emphasized by considering the opposite of dissociation, namely, association. In contrast for example to the complete dissociation at infinite dilution, an acid is completely associated when it is anhydrous. Thus chemically pure and absolutely water free sulphuric acid does not possess any of the ordinary properties of an acid. Blue litmus and the ordinary metals such as sodium, if actually dry, remain entirely unaffected by it. There are other striking examples illustrating the importance of the presence of water. Sulphur and phosphorus will not burn in dry oxygen. Hydrochloric acid if dry will react neither with dry carbonates nor even with dry ammonia. ${ }^{8}$

The dissociation which occurs in ordinary solutions is usually measured by physicochemical methods and in 
order to avoid any possible confusion it is often convenient to use the expression "physicochemical reaction" though obviously a solution cannot have more than one reaction.

The titration value of a solution is, necessarily, a broader term than reaction, since it includes not only the free hydrogen and hydroxyl ions present, but all the reserve of undissolved and undissociated hydrogen or hydroxyl which can be liberated as ions. Even in the case of a mineral acid dissolved in water, the titration value is greater than the actual reaction except at a dilution of infinity, since for all dissociated hydrogen ions there is invariably a definite and fixed amount of undissociated hydrogen that will dissociate upon neutralization of the free hydrogen ions.

Some slight confusion has arisen from the fact that certain substances though virtually neutral when tested electrometrically, nevertheless give a distinctly acid or alkaline reaction with ordinary standard indicators. This somewhat perplexing situation is readily understood when it is remembered that these indicators themselves are either weak acids or bases and are capable of changing slightly the ionization of the fluids to which they are added. The error lies in the assumption that these indicators are neutral; moreover the ordinary indicators vary greatly among themselves as regards the amount of hydrogen or hydroxyl ions that is required to overcome their own reaction and produce a change in color.

The theoretical consideration on which this discussion rests is illustrated in the accompanying outline showing the behavior of various substances toward indicators and acids under different conditions. 
THE REACTION AND TITIRATION VALUES OF VARIOUS SUIBSTANCES

\begin{tabular}{|c|c|c|c|c|}
\hline $\begin{array}{l}\text { Substances } \\
\text { nnder } \\
\text { examination }\end{array}$ & $\begin{array}{l}\text { Reaction } \\
\text { (physico- } \\
\text { chenical) }\end{array}$ & $\begin{array}{l}\text { Behavior } \\
\text { with } \\
\text { indicators }\end{array}$ & $\begin{array}{l}\text { Effect of moder- } \\
\text { ate addition of } \\
\text { acid }\end{array}$ & $\begin{array}{c}\text { Titration } \\
\text { value }\end{array}$ \\
\hline Distilled water & Neutral & Neutral & Becomes aeid & None \\
\hline $\begin{array}{l}\text { Suspension of } \\
\mathrm{CaCO}_{3} \mathrm{in} \text { water }\end{array}$ & Neutral & Neutral & $\begin{array}{l}\text { Remains neu- } \\
\text { tral }\end{array}$ & Iligh \\
\hline Blood serum & $\begin{array}{l}\text { Faintly al- } \\
\text { kaline }\end{array}$ & $\begin{array}{l}\text { Distinctly al- } \\
\text { kaline to lit- } \\
\text { mus, methyl } \\
\text { orange, etc.; } \\
\text { acid to phen- } \\
\text { olphthalein }\end{array}$ & $\begin{array}{l}\text { Alkaline, neu- } \\
\text { tral or acid }\end{array}$ & Moderate \\
\hline $\begin{array}{l}\text { Anhydrous } \\
\mathrm{H}_{2} \mathrm{SO}_{4}\end{array}$ & Neutral & Neutral $\dagger$ & $\cdots$ & High \\
\hline $\begin{array}{l}\mathrm{H}_{2} \mathrm{SO}_{4} \text { at high } \\
\text { dilution }\end{array}$ & Acid & Aeid & $\cdots$ & $\begin{array}{l}\text { Practically } \\
\text { equivalent to } \\
\text { physicochem- } \\
\text { ical reaction }\end{array}$ \\
\hline
\end{tabular}

* According to amount added. $\quad$ Under anhydrous conditions.

In speaking of the physicochemical reaction of a solution, even in case of the faintly alkaline blood serum, it must be emphasized that an increase in the hydrogen ion concentration does not by any means imply that the solution has become acid. This becomes selfevident when we remember that the reaction can be stated equally well in terms of the hydroxyl ion concentration. The mere presence of hydrogen ions does not indicate, in any way, whether the solution is acid or alkaline, since even in the strongest solutions of acid 
and alkali, both hydrogen and hydroxyl ions are constantly present, a definite equilibrium existing between the two. Thus if a ten per cent solution of caustic soda is reduced to a strength of five per cent by neutralization or by dilution then there has been a marked increase in its hydrogen ion concentration though the solution remains strongly alkaline. This principle is not infrequently overlooked in the interpretation of the data obtained on blood serum even by workers in this field. 


\section{EQUILIBRIUM BETWEEN $\Lambda$ CIDS AND BASES}

Normal Conditions. The highly important procedure of disposing of the excess of acid radicals arising in metabolism and of maintaining a constant reaction of the blood is accomplished by a mechanism which is extremely efficient and also comparatively simple. Moreover, this mechanism is in active operation in health as well as in acidosis. Even in an omnivorous diet the acid radicals arising from the combustion of sulphur, phosphorus and carbon exceed the bases which are present. This excess of acid is corrected not by any spontaneous or artificial change in the diet but by the processes of oxidation, excretion and neutralization. The handling of the carbon is a relatively simple problem, since it is readily oxidized, the resulting carbon dioxide being eliminated by the lungs as such and by the kidneys after conversion to urea. A limited amount of the acids arising from the sulphur and phosphorus are neutralized by the fixed bases of the body. The striking feature, however, consists in the ability of the kidney to excrete a sharply acid urine from a slightly alkaline blood plasma. But alkalies can also be eliminated equally well. Thus the kidney regulates the composition of the blood in its finer details, excreting the acid or alkaline phosphates and carbonates according as conditions may require. Henderson ${ }^{9}$ has pointed out and established that the mono- and di-sodium phosphates and carbonates of the blood constitute one of the fun- 
damental features in the regulation of neutrality, since the mono-sodium salt $\left(\mathrm{NaH}_{2} \mathrm{PO}_{4}\right)$ is acid and the disodium salt $\left(\mathrm{Na}_{2} \mathrm{HPO}_{4}\right)$ is alkaline to litmus. It might appear at first glance that a mixture of these phosphates in aqueous solution would react readily with acid or alkali with a corresponding change in the reaction of the solution. On the contrary, although chemical combination takes place, the reaction does not change until after the addition of considerable amounts of acid or alkali, since a readjustment of the proportions of monoand di-basic phosphates occurs. The normal carbonate and bicarbonate of the serum act in a similar though somewhat less effective manner. Henderson has emphasized that this mixture of phosphates and carbonates is the most effective which could be devised for maintaining a constant reaction; it is extremely efficient not only in aqueous solution but in the presence of colloids, such as serum affords, its value is distinctly enhanced. The colloids by their amphoteric nature are able to take up very appreciable amounts of acid or base without changing their reaction. But this remarkable stability of the blood even in coöperation with the kidney is not sufficient to care for the excess of phosphoric and other acid end-products under normal conditions. A third very important step consists in securing another source of alkali in addition to that which occurs in the food. This is accomplished in the course of the metabolism of nitrogen through the interception and neutralization of ammonia by the acid radicals. It is generally accepted that, for all practical purposes, ammonia occurs in the urine physiologically only to the extent which it is needed for the neutralization of acid, the remainder of the ammonia being 
promptly converted to urea. 'The evidence for this view consists chiefly in the fact that in normal individuals the feeding of sodium biearbonate causes a prompt fall in the ammonia output in the urine. Indeed, there is only a negligible residuum of ammonia (about onehalf per cent of the total urinary nitrogen) which cannot be replaced by feeding alkali. ${ }^{10}$

In summarizing the mechanism of the normal equilibrium between acids and bases as it occurs in health, we have on the one hand a liberal production of acids arising in the main from the combustion of carbon, phosphorus and sulphur. Nevertheless, a slightly alkaline reaction of the blood is constantly maintained, primarily by the following means:

1. Intake of fixed bases in the food.

2. Elimination

(a) of carbon dioxide by the lungs,

(b) of acid by the kidney.

3. Neutralization of acid in the body by ammonia. In the metabolism of acids, it is seen that one of the extremely important factors is the process of oxidation. By this means, the organic acid radicals are practically destroyed being burned to carbon dioxide; at the same time considerable quantities of mineral acids are produced from the proteins and these cannot be oxidized further. In either case after the preliminary step of oxidation, the end-products are disposed of by two general processes, namely, (1) excretion and (2) neutralization.

Pathological Conditions. The maintenance of a proper reaction of the blood, although a very simple matter in health, may even with extensive artificial aid become a difficult problem in disease. The measures for thera- 
peutic purposes will be discussed subsequently and it is necessary to consider here only those means by which the body spontaneously protects itself against an accumulation of acid. This protection is accomplished in fundamentally the same manner in health and in disease. In the latter case, even under extreme conditions, the body responds not by the development of a new method for the disposal of acids but by a quantitative increase in its normal processes. Certain features, however, which are not conspicuous under normal conditions become more prominent under the tension of the state of acidosis and the increase in the normal compensatory processes is not altogether evenly distributed among the various factors. Considering first the excretory processes, the elimination of carbon dioxide is readily accomplished as long as fixed bases are available to permit of its transportation to the lungs. In the case of the kidney, however, the margin of safety is small indeed since the amount of organic or mineral acids which it can excrete is not very significant in comparison to the quantities which sometimes must be disposed of in acidosis. If excessive amounts tend to accumulate or if the kidney is damaged, then other methods must be found for disposing of this excess. There is a certain reserve of fixed alkali which can be drawn upon to a limited extent without disturbing the body metabolism. This source of supply is not large and under certain conditions, especially in diabetes, the bulk of the increased work falls upon the process of neutralization by ammonia. Fortunately there is a large excess of nitrogen from the catabolism of proteins which is available for this purpose; under normal conditions only a small fraction of the total nitrogen of the 
urine (about two to five per cent) is utilized for the neutralization of acids. In acidosis proportionately much more (ten to forty per cent) of this nitrogen is intercepted by acid. Notwithstanding this remarkable increase in the ammonia output and the efficiency of Henderson's factor as regards the composition of the blood, the fixed bases gradually become depleted. The efficiency of the compensatory processes is determined not by the height of the ammonia coefficient, but the crucial test of these processes consists in their ability to protect and conserve the supply of fixed bases or base yielding substances in the blood and other tissues.

The necessity of avoiding a marked acidosis is evident when we consider the importance of these bases in metabolism. Normally oxygen is carried by the arterial blood from the lungs to the tissues where the carbon is burned and the resulting carbon dioxide is carried as carbonate, largely sodium bicarbonate, by the venous blood to the lungs, where the bicarbonate breaks up, the carbon dioxide is exhaled, the normal carbonate returning by the arterial blood to the tissues to take up and carry away more carbon dioxide. With the depletion of the carbonates, the oxygen is still carried by the arterial blood but the resulting carbon dioxide gradually accumulates in the tissues, since there is not an adequate supply of bases for transporting it to the lungs. With this accumulation of carbon dioxide, the tissues are no longer able to utilize the oxygen brought to them; ${ }^{*}$ the individual becomes dyspnoeic and suffers from subjective symptoms of suffocation just as though he were deprived of air. The oxygen, since it cannot

* This is the usual explanation though the evidence in support of it is not altogether complete. 
be taken up by the tissues, remains in the venous blood, giving it an arterial color, the blood in the veins ordinarily being dark simply by reason of the withdrawal of oxygen, rather than on account of the presence of carbon dioxide. This exhaustion of carbonates leads first to the development of air hunger and eventually to death if the exhaustion is sufficiently extreme. The cardinal feature of acidosis is, that there is neither an increased production nor an accumulation of acid in the body, but the reserve supply of alkali yielding substances is depleted in the prevention of the appearance of acid in the blood.

In contrast to acidosis, it may be well to consider briefly the hypothetical possibility of the so-called "alkalosis." Experimentally, it is of course a simple matter to kill animals with massive injections of alkali. However, under conditions that arise spontaneously in man or lower animals, there is no evidence that excessive amounts of alkali can accumulate in the body. Such an excess is readily avoided, by a reduction in the amount of ammonia which is intercepted for the neutralization of acids, and by the excretion of alkali by the . kidney. In some recent papers, Wilson ${ }^{11}$ and his collaborators have brought forth some highly interesting facts on the ameliorating effect of acidosis upon parathyroid tetany. These authors find that periods of alkalosis develop spontaneously before an attack of tetany and are succeeded by periods of acidosis during or after the attack. Also, beneficial results were obtained by the administration of acid. According to these findings, the removal of the parathyroids produces a state of alkalosis which is responsible, in part, for the development of tetany; if this alkalosis is corrected or 
over corrected, spontaneously or by the administration of acid, then the tetany is relieved. Alkalosis, then, as designated by Wilson consists in an increase in the basic radicals of the blood; this inerease may be absolute or there may be a decrease in the production of acid radicals (except carbon dioxide) resulting in a relative excess of basic radicals. In either case the resulting physicochemical reaction of the blood may remain unchanged. While these facts bearing upon the relief of parathyroid tetany are highly important, the interpretation of them on the basis of an alkalosis is not adequately supported by the experimental data. The evidence of the existence of acidosis consisted in the determination of (1) the dissociation constant of oxyhaemoglobin, (2) the carbon dioxide content of the alveolar air, (3) the hydrogen ion concentration of the blood, (4) the ammonia output in the urine, (5) the hydrogen ion concentration and total acidity of the urine. Unfortunately it is necessary to emphasize that one of the technical methods employed was at fault, namely, the reaction to indicators of the dialysate from blood serum does not represent the hydrogen ion concentration of the blood. The examination of the reaction of the urine is of importance on account of its bearing upon alkalosis. A diminution in acidity was frequently found but nevertheless there was, almost constantly, a distinet preponderance of acid radicals, considerable acid and ammonia being excreted in the urine. In exceptional instances an alkaline urine was obtained. In the presence of definite amounts of ammonium salts, such a reaction is without significance in the absence of ehemical or bacteriological data to determine whether this alkalinity was due to fixed bases or to ammonium hydroxide. Moreover, the 
occasional voiding of an alkaline specimen of urine would not be conclusive proof of alkalosis, even though the alkalinity be due to fixed bases. This interesting fluctuation in the excretion of acid after parathyroidectomy does not establish that there was a preponderance of the basic radicals over the acid end-products or that there was an increase in the reserve supply of alkali in the body.

In considering the hypothetical possibility of an absolute excess of fixed bases in the body, it is difficult to see from what source these bases could be obtained other than the limited amount occurring in the food supply or how they could escape excretion by the kidney or neutralization by acids. The protein metabolism yields a large supply of acids which is readily available for the neutralization of bases; even the excessive amounts of ammonia, such as occur in acute yellow atrophy, do not by any means exhaust the supply of acid radicals. In a search for the condition of alkalosis one should be cautious about interpreting an increase in the carbon dioxide content of the alveolar air as indicating an increase in the carbonates of the blood. It may mean simply that an unusually large proportion of the normal carbonate is converted in the lungs to bicarbonate, i. e., that there is a change in the relative proportion of the two salts without a change in the total quantity. The occurrence of alkalosis, in the sense of a relative or absolute excess of alkali reserve over the normal, in the blood and body tissues, has not been established; on a priori grounds, it is difficult to conceive that the protein metabolism in normal or pathological conditions could diminish spontaneously to the point where an alkalosis would prevail. 


\section{III}

\section{METIIODS OF DIAGNOSING ACIDOSIS}

Clinical Signs. The state of acidosis is accompanied by certain clinical manifestations one of which is very characteristic. In advanced cases, the respiration becomes moderately rapid; the striking feature in uncomplicated cases is not the increase in rate but the pronounced increase in depth with a somewhat prolonged expiration. This dyspnoea is accompanied not by cyanosis but by a bright color, even at times an abnormally bright color, of the mucous membranes. Physical examination of the chest shows nothing to account for this labored respiration. Such a picture constitutes a typical air hunger and is a very characteristic symptom provided that no complicating factors are present. It occurs, however, only in advanced stages of acidosis.

Laboratory Methods. For the detection of the earlier stages, a fruity odor of the breath is of course very helpful in diagnosing diabetic acidosis but it is preferable to consider here only the general methods applicable to all types. A variety of laboratory methods are available. These may be conveniently listed as follows:

I. Examination of the blood for

1. lowering of alkalinity,

2. lowering of carbon dioxide content.

II. Examination of respiration for lowering of carbon dioxide tension in alveolar air. 
III. Examination of urine for

1. excess of acid or for abnormal acids,

2. change in fixed bases,

3. increase in ammonia output.

Of this list it is obviously desirable to select some clinical method which shall be firstly, sufficiently delicate to detect the early grades, and secondly, shall be applicable to all types regardless of etiology and in the third place shall be pathognomonic of acidosis.

In the examination of the blood, titration methods for changes in alkalinity are notoriously inadequate. The proteins of the serum interfere seriously with the end point and the measurement involves comparatively slight changes. The results of the titration methods are at best only suggestive, even in outspoken acidosis, and are without value in early cases. In contrast to the titratable alkalinity one can, with sufficiently elaborate equipment, determine accurately the physiocochemical reaction of the blood. It has finally been demonstrated, however, that this determination is without clinical interest. This result was predicted by Folin ${ }^{2}$ when the physiocochemical methods were introduced into biology and at a time when there was a tendency to begin to look upon the titration values of fluids as being without biological significance. It was first shown by Benedict ${ }^{12}$ in 1906 that, by virtue of the compensatory processes of the body, the reaction of the blood remains practically constant even in outspoken acidosis. It is only in the terminal stages of a fatal case that a demonstrable increase takes place in the hydrogen ion concentration of the blood and even then it is measurable only with delicate equipment. This result has been confirmed by a number of observers but more especially in this country 
by Peabody. ${ }^{27}$ In a sense, it is perhaps more nearly true to say that the hydrogen ion concentration of the blood remains constant even in fatal acidosis than to give the impression that a significant increase occurs. So delicate have the scientific measurements become that changes in electrical conductivity can be detected which approach the vanishing point. 'Thus of the trustworthy obscrvations, the maximal change of the hydrogen ion concentration in fatal acidosis has been reported by Peabody. In the most extreme instance the decrease in alkalinity, as compared with the average normal, was equivalent to a solution about five hundred-millionths normal. $(0.000,000,056$ for $\mathrm{PH} 7.45$ and 7.04.)

Occasionally work is reported which is interpreted as indicating that the hydrogen ion concentration changes rather easily even in mild degrees of acidosis. The results of Hasselbalch and Gammeltoft ${ }^{13}$ have been sometimes quoted in support of this idea. These authors investigated the reaction of the blood during pregnancy. From the estimation of the ammonia in the urine and the carbon dioxide of the alveolar air they concluded that a very slight degree of acidosis occurs late in pregnancy. In 12 cases, the physicochemical reaction of the blood was entirely within normal limits except for an occasional isolated analysis in one or two cases showing an insignificant increase in the hydrogen ion concentration not definitely beyond the limits of error. In contrast to these results Michaelis, ${ }^{66 \mathrm{a}}$ in the study of a series of 23 cases of pregnancy, found an extremely slight decrease in the hydrogen ion concentration; this author felt that the changes were apparently slightly greater than the limits of error of his method. A very striking divergence from this view of 
the constancy of the physicochemical reaction of the blood has been reported by Rowntree. ${ }^{14}$ The results are based upon the behavior to indicators of the dialysate from blood serum. In marked contrast to the advanced cases of acidosis showing only slight changes even at death, Rowntree reports rather wide fluctuations in the hydrogen ion concentration; moreover these occasionally occurred in conditions in which there was comparatively little evidence of acidosis. The wide variations obtained by this colorimetric method do not affect the general conclusion regarding the constancy of the reaction of the blood as established by numerous determinations of various workers using standard physicochemical equipment. Indeed any method for the detection of moderate grades of acidosis, depending upon the changes in the hydrogen ion concentration of the blood, could only be considered in the light of our present knowledge, as being based upon a faulty principle, since it is established that no change occurs except in advanced stages.

In the consideration of acidosis, the carbon dioxide content of the blood and alveolar air are so closely interdependent that for general purposes they may be considered together. They depend of course upon a common factor, i. e., the content of the blood in carbonates and ordinarily the agreement between them is very close. This has been demonstrated in a recent study by Walker and Frothingham. ${ }^{15}$ In a series of over 100 observations on thirty different types of disease, significant variation in these factors occurred in very few instances. The analysis of the carbon dioxide content of the blood is now feasible as a laboratory procedure by the principle recently devised by Van Slyke, 
Cullen and Stillman. ${ }^{16}$ The determination of the carbon dioxide content of the alveolar air is even simpler by the ingenious method recently devised by Marriott; ${ }^{17}$ if this method is employed, one should be in a position to standardize the results occasionally with more elaborate equipment. Unfortunately the carbon dioxide content is lowered by conditions other than acidosis or at least in which the existence of acidosis has yet to be established. The most significant paper bearing on this point is that of Porges, Leimdörfer and Markovici. ${ }^{18}$ In a series of advanced cardiac cases, many of which were decompensated, but without prominent signs of nephritis, they found a pronounced lowering of the carbon dioxide tension of the alveolar air. Similar changes are observed in normal people accustomed to living at high altitudes but other evidences of acidosis have not been demonstrated in these individuals. ${ }^{19}$

There are at least two general groups of factors other than acidosis which lower the carbon dioxide tension in the alveolar air, namely (1) increased pulmonary ventilation as illustrated by the effect of high altitudes and (2) any change in the lungs or in the circulation which would interfere with the exchange of gases between the alveolar air and the blood. Such changes probably account for the low values found in some of the cardiac cases. A moderate fall in the carbon dioxide content of the blood or alveolar air is not adequate proof of the existence of acidosis in unknown conditions without the support of confirmatory evidence.

Such confirmation may often be obtained from the examination of the urine. One may search either for the presence of abnormal acids or for evidence of excessive excretion either of free acids or their neutral salts. 
The neutralization of acid by fixed bases leads to the excretion of an excess of sodium, potassium, calcium and magnesium in the urine. Cammidge ${ }^{20}$ has studied the excretion of these elements and the results are of interest and importance. When considered as a clinical test, two serious objections present themselves. The determination of even the calcium and magnesium is too complicated a procedure for routine work. Moreover, the excretion of calcium and magnesium may decrease rapidly even in advanced grades of acidosis on account of a depletion in the supply of available amounts of these salts in the body. Consequently the determinations must be made not on any single day but throughout the entire period of acidosis if their significance is to be properly interpreted.

The one most serious objection to searching for the appearance of acids not encountered in normal urine is that such a procedure cannot constitute a general method for determining the presence or absence of acidosis in an unknown condition. Since these new acids might vary widely in different acidoses, negative results might merely indicate failure to recognize some unknown acid. Theoretically it is not even necessary that excessive amounts of acid should appear in the urine in the development of an acidosis, but on the contrary even the normal amount of acid may be diminished in case of impairment in the ability of the kidney to excrete acid. Even when the kidney is normal the determination of the total daily acidity is not helpful either as a means of detection or as a method of measurement of the degree of acidosis.

The choice of methods might seem to fall upon the determination of ammonia; for, while it is markedly 
increased in certain primary disturbances of protein metabolism in which no acidosis is present, yet a normal ammonia output might seem to exclude acidosis. $A$ priori, however, this does not follow. None of these procedures are entirely adequate for a thorough study of unknown conditions. It is now established that fatal acidosis may occur with a normal or subnormal output of ammonia and under conditions in which there is no disturbance of carbohydrate metabolism. 'These rather radical modifications in our conceptions of acidosis have come about through the study of various types of kidney disease. In order to form a comprehensive view of these fundamental changes it is necessary to review in detail the methods by which the occurrence of acidosis in the nephropathies has been demonstrated. 


\section{IV}

\section{BEHAVIOR OF THE BODY IN HEALTH AND IN ACIDOSIS TOWARDS SODIUM BICARBONATE}

The constancy of the physicochemical reaction of the blood even in the outspoken stages of acidosis does not in any sense imply that there is but little change from the normal in the body metabolism. In fact it is only by extensive compensatory changes that the reaction is maintained at a constant value. The underlying problem in the diagnosis of acidosis consists in the detection of the changes by which this compensation is effected. Inasmuch as the ultimate object of this compensation is the conservation of the supply of fixed bases, it would be desirable to study the content of the tissues in these bases and their rate of excretion. For the reasons that have already been pointed out the direct analysis of the urine for calcium, magnesium, sodium and potassium is a complicated procedure. Moreover, in addition to determining the composition of the urine, it is equally desirable to learn whether the blood and other tissues of the body have become depleted in these bases. To arrive at this information, it occurred to me to take advantage of the following indirect procedure. ${ }^{21}$ Under normal conditions, the ingestion of a small amount of sodium bicarbonate ( 5 grams) is promptly followed by the excretion of at least part of this amount in the urine, the reaction of the urine to litmus paper changing from acid to alkaline. In a physiological sense, the tissues are saturated with alkali 
and the excess is promptly eliminated. However, if some depletion has occurred, the bicarbonate upon introduction is stored in the tissues to make up this deficit and the urine remains acid in its reaction. One of the essential features in the development of this phenomenon for detecting acidosis consists in determining the delicacy of such a test. Its sensitiveness would depend primarily upon two factors, namely, (1) whether an early depletion of fixed bases, even though very slight, takes place in acidosis and (2) whether the tissues when slightly depleted in bases will take up and store alkali before the kidney can excrete it. In order to answer these questions, the behavior of the body to bicarbonate was studied in some acidoses occurring spontaneously and in others of slight degree which were produced experimentally.

The use of bicarbonate as a diagnostic test for acidosis was first investigated in the study of a series of cases of Asiatic cholera; in this disease, renal complications occur with great intensity, developing in many instances into uraemia with a rather typical air hunger. Cases in the stage of reaction in which nephritis had developed showed an outspoken tolerance to sodium bicarbonate, the urine very frequently remaining sharply acid after the intravenous injection of 30,60 and even 90 grams of sodium bicarbonate; in normal individuals the injection of 3 to 5 grams rendered the urine alkaline. ${ }^{21}$

It does not necessarily follow that this failure to excrete the bicarbonate was due either to the nephritis of Asiatic cholera or that it was even the result of an acidosis. At the time this work was carried out, it seemed extremely probably that the tolerance was related directly to the renal lesions, rather than to the enteritis, 
and that it constituted an acidosis. In order to decide these points the first step obviously consisted in determining whether this same tolerance occurs in nephritis from other causes. In Manila where the cases of cholera were studied, uncomplicated cases of nephritis with typical uraemia are not very common. Somewhat later, however, some ordinary nephritics were studied in Baltimore. ${ }^{22}$ It was found in several instances that the bicarbonate was readily excreted even in outspoken cases of the chronic parenchymatous type. However, in the chronic interstitial type, in the arteriosclerotic group and in acute cases, a high degree of tolerance was present which was often equal to or greater than that found in cholera nephritics. Moreover, some of these cases were free from any bacterial infection. This proves that the increased tolerance occurs independently of the infection with the cholera vibrio and also independently of other infections as well. This behavior to bicarbonate in renal disease has been demonstrated independently of my own work by Palmer and Henderson. ${ }^{23}$ Obviously, however, this finding does not constitute proof of acidosis in nephritis. From this evidence alone, it is altogether impossible to decide whether retention of bicarbonate is due, on the one hand, to an inability of the diseased kidney to excrete alkali even after massive injections have been used with a resulting accumulation of an enormous excess of carbonate in the body, or on the other hand, whether the diseased kidney can excrete carbonates in an approximately normal manner and the tissues are storing the injected carbonates to replace a deficit existing in the body.

There is considerable evidence that this tolerance represents essentially a deficit in bases, i. e., that it con- 
stitutes an acidosis. One striking feature is the effect of repetitions of the injections in nephritic patients. Many of these cases require relatively enormous amounts of bicarbonate, 100 grams or more at the first test, to render the urine alkaline. It is characteristic of these cases that after the injections are discontinued and the urine has again become acid, a small dose of bicarbonate (5 grams) is often sufficient to render the urine alkaline. It is very tempting, indeed, to look upon this result as proof of acidosis. Indeed, this finding has even been interpreted in the literature ${ }^{23}$ as crucial evidence in the distinction between acidosis and renal retention, a conclusion which is not fully justified. Experimental demonstration, however, of the exact signficance of this finding constitutes a rather tedious problem; from one standpoint the prompt effect of this small second injection is exactly the result that one would expect if the threshold of the kidney for the excretion of bicarbonate had been raised, the impairment of renal function requiring that excessive amounts be present in the blood before any bicarbonate could pass the kidney. After a sufficiently massive dose of bicarbonate had been injected, additional small doses would be excreted by the kidney, since the body presumably could not rid itself promptly of this large injection of bicarbonate. Indeed it is rather striking that the behavior of nephritic patients to bicarbonate is just the reverse of the results in classical diabetic acidosis. In the treatment of diabetic coma one of the distressing features is the promptness with which acidosis returns. Thus it frequently requires rather heroic injections of alkali to overcome the acidosis and render the urine temporarily alkaline. In a few hours with the 
return of the acid reaction of the urine, it is often found that instead of a small dose of alkali, massive injections are again required to bring back the alkaline reaction.

The differentiation between a deficit of bases and renal retention of an excess of bicarbonate is evidently of fundamental importance. Although the natural interpretation is that of acidosis (bicarbonate deficit), yet it is not altogether a simple matter to support this hypothesis with exact proof. Successive repetitions at short intervals of the determination of the tolerance to bicarbonate in the same individual are clearly inadequate to solve this problem since, theoretically, one would obtain precisely the same result either in the case of renal retention or in a slowly developing acidosis. Consequently, it becomes necessary to devise other methods.

In the solution of this problem, the following evidence was collected: ${ }^{24}$

1. Determinations showing that the injected bicarbonate is not excreted by way of the intestine.

2. Demonstration that a deficit of fixed bases exists in the body and that the bicarbonate does not accumulate in excessive amounts in the blood.

3. Determinations showing a marked lowering of the carbon dioxide content of the blood in uraemia.

It is not a difficult matter to prove that the injected bicarbonate is not excreted as such from the body. Examination of the urine excludes the possibility of excretion as such by the kidney as long as the urine remains sharply acid. In some fatal cases of uraemia, which had received massive injections, examination of the stools during life and of the intestinal contents at autopsy 
showed no fixed bases. The stools and intestinal contents were either acid in reaction, or where an alkaline reaction was obtained, the alkalinity was due to ammonium salts and not to fixed bases. In order to distinguish between ammonia and the fixed bases, those stools which were alkaline were diluted with water and boiled over a free flame, the volume being maintained by the addition of water. Ammonia was driven off in the steam and the reaction of the liquid became neutral or acid.

After determining that the bicarbonate was not eliminated from the body, it was necessary to establish whether it was retained as such in the tissues to replace a preëxisting deficit with elimination in the urine as soon as this deficit was replaced and also to determine whether any accumulation in excess of the normal occurred. The most direct method for investigating these points would consist in the estimation of the titratable alkalinity of the blood. This was accomplished indirectly by the determination of the carbonates as carbon dioxide and directly by the use of indicators. The usual titration methods of whole serum with indicators are not sufficiently definite to admit of rigid conclusions. A simple qualitative method was devised by which it was possible to detect a diminution in titratable alkalinity of the blood and to determine the fate of the injected bicarbonate. ${ }^{25}$ The basis of this method is that normal blood serum reacts as an acid to phenolphthalein but heated serum reacts alkaline. In order to render the test more sensitive, the interfering proteins were removed by alcohol. The titratable value of the proteins is lost in this procedure but the object of this test is to detect qualitative changes with absolute certainty rather than to attempt the accurate measurement of 
comparatively small quantitative changes under unfavorable conditions. A simple way of carrying out this test is as follows: one c.c. of serum is shaken thoroughly for a moment with 25 c.c. of absolute alcohol and the alcohol filtered off. The filtrate with a few drops of phenolpthalein is evaporated to dryness. With normal human serum, the residue is always red. In mild grades of acidosis, the residue is either colorless or, on close observation, one may detect just a trace of pink color, but an intense red color appears on adding a drop of water. In more marked grades of acidosis, the residue is colorless and remains colorless on adding water. In extreme cases, the diluted serum without removal of proteins, when boiled, remains colorless upon the addition of phenolphthalein. The value of this method was tested both by experimentation in vitro and in vivo. Small amounts of acid were added to blood serum. This addition of acid could be detected much more readily by testing the reaction to phenolphthalein than by titrating against standard acid using dimethylamidoazobenzene ('Töpfer's reagent) as indicator. Experimental acidosis in animals and spontaneous acidosis arising in man could also be detected very readily. ${ }^{25}$ All nephritics which show an increase in tolerance of 20 to 30 grams or more of sodium bicarbonate also show changes in blood when tested in this manner with phenolphthalein. The results of the examination of the blood in a typical case of uraemia and the effect of the injection of bicarbonate are presented in some detail, since two important conclusions are drawn from these findings. The data prove in the first place that the diseased kidney can excrete bicarbonate very readily, and secondly, that a method is afforded for 
demonstrating the existence of definite acidosis rather early in the course of nephritis. These conclusions are based upon a preliminary study of fourteen cases ${ }^{22}$ followed by a more complete study of seventeen additional cases. ${ }^{24}$ The following table illustrates typical cases:

TITRATABLE ALKALINITY OF TIIE BLOOD IN URAEMIA AND THE EFFECT OF TIE INJECTION OF SODIUM BICARIBNATE

\begin{tabular}{|c|c|c|c|c|c|c|c|c|}
\hline \multirow{2}{*}{ Case } & \multirow{2}{*}{$\begin{array}{c}\text { Sodium } \\
\text { bicar- } \\
\text { bonate }\end{array}$} & \multirow{2}{*}{$\begin{array}{c}\text { Interval } \\
\text { after } \\
\text { injec- } \\
\text { tions }\end{array}$} & \multicolumn{3}{|c|}{$\begin{array}{l}\text { Behavior of serum towards } \\
\text { phenolphthalein after re- } \\
\text { moval of protein }\end{array}$} & \multirow{2}{*}{$\begin{array}{l}1-10 \mathrm{di}- \\
\text { lution } \\
\text { of whole } \\
\text { serum } \\
\text { in water }\end{array}$} & \multirow{2}{*}{$\begin{array}{c}\text { Carbon } \\
\text { dioxide } \\
\text { in blood } \\
\text { (volume } \\
\text { per } \\
\text { cent) }\end{array}$} & \multirow{2}{*}{$\begin{array}{c}\text { Reaction of } \\
\text { urine to } \\
\text { litmus }\end{array}$} \\
\hline & & & $\begin{array}{l}\text { Alco- } \\
\text { holic so- } \\
\text { lution of } \\
\text { residue }\end{array}$ & $\begin{array}{l}\text { Residue } \\
\text { after } \\
\text { evapo- } \\
\text { ration }\end{array}$ & $\begin{array}{l}\text { Aqueous } \\
\text { solution } \\
\text { of } \\
\text { residue }\end{array}$ & & & \\
\hline 1 & $\begin{array}{l}\text { Before in- } \\
\text { jection } \\
60 \mathrm{gm} \text {. } \\
60 \mathrm{gm} \text {. } \\
30 \mathrm{gm} \text {. }\end{array}$ & $\begin{array}{c}\ldots . \\
12 \text { hrs. } \\
12 \text { hrs. } \\
8 \text { hrs. }\end{array}$ & $\begin{array}{l}\text { No color } \\
\text { No color } \\
\text { No color } \\
\text { Red }\end{array}$ & $\begin{array}{l}\text { No color } \\
\text { No color } \\
\text { Pink } \\
\text { Red }\end{array}$ & $\begin{array}{l}\text { No color } \\
\text { Pink } \\
\text { Red } \\
\text { Red }\end{array}$ & $\begin{array}{l}\text { No color } \\
\text { Pink } \\
\text { Red } \\
\text { Red }\end{array}$ & $\begin{array}{l}20 \\
\ldots \\
\ldots \\
44\end{array}$ & $\begin{array}{l}\text { Acid } \\
\text { Acid } \\
\text { Acid } \\
\text { Neutral }\end{array}$ \\
\hline$q$ & $\begin{array}{l}\text { Before in- } \\
\text { jection } \\
30 \mathrm{gm} \text {. } \\
30 \mathrm{gm} . \\
20 \mathrm{gm} \text {. }\end{array}$ & $\begin{array}{c}\ldots \ldots \\
20 \mathrm{hrs} . \\
20 \mathrm{hrs} . \\
5 \mathrm{hrs} .\end{array}$ & $\begin{array}{l}\text { No color } \\
\text { No color } \\
\text { Red } \\
\text { Red }\end{array}$ & $\begin{array}{l}\text { No color } \\
\text { No color } \\
\text { No color } \\
\text { Red }\end{array}$ & $\begin{array}{l}\text { No color } \\
\text { Pink } \\
\text { Red } \\
\text { Red }\end{array}$ & $\begin{array}{l}\text { No color } \\
\text { Red } \\
\text { Red } \\
\text { Red }\end{array}$ & $\begin{array}{c}\ldots \\
\cdots \\
50\end{array}$ & $\begin{array}{l}\text { Acid } \\
\text { Acid } \\
\text { Acid } \\
\text { Slightly } \\
\text { alkaline }\end{array}$ \\
\hline Normal & $5 \mathrm{gm}$. & $\ddot{3 \text { hrs. }}$ & $\begin{array}{c}\text { Red } \\
\ldots\end{array}$ & $\begin{array}{c}\text { Red } \\
\ldots\end{array}$ & $\begin{array}{c}\text { Red } \\
\ldots\end{array}$ & $\begin{array}{l}\text { Red } \\
\ldots\end{array}$ & $\begin{array}{c}40 \text { to } 50 \\
\ldots\end{array}$ & $\begin{array}{l}\text { Acid } \\
\text { Alkaline }\end{array}$ \\
\hline
\end{tabular}

In this table the colorless reaction to phenolphthalein shows that originally the blood was seriously depleted in fixed bases. With the successive injections of bicarbonate, the reaction to phenolphthalein passes through the various stages showing that the carbonate content of the blood is gradually increasing. During these injections the urine remains acid in reaction, until the 
point is reached at which the blood serum reacts normally; then a further injection of alkali causes the urine to become alkaline.

Confirmation of these conclusions was obtained by determining the carbon dioxide content of venous blood. For making these determinations, a modification was devised of Warburg's method for estimating small amounts of carbon dioxide. ${ }^{24}$ This modification was developed, not for the purpose of providing a routine method, but rather to determine accurately whether a definite and significant drop in carbon dioxide occurs in uraemia. This is of considerable importance since an extreme fall in the carbon dioxide content of the venus blood is virtually pathogonomonic of acidosis. The results showed a pronounced lowering. In four typical cases of uraemia the values ranged from 10 to 24 per cent, calculated as volumes per cent, instead of a normal of 40 to 50 per cent.

This evidence, obtained then from the examination of the stools and urine and the titratable alkalinity and carbon dioxide content of the blood, gives absolute proof that the tolerance to fixed bases in nephritis is due essentially to a deficit of the body in bases and not to an inability of the kidney to excrete bases nor to vicarious excretion of bicarbonate by the intestine. This evidence is supported by a variety of circumstances but it constitutes the only exact proof which we have that this increase in tolerance in early cases of nephritis is due, primarily, to a deficit in fixed bases and not to a retention of the injected carbonate in excess of the normal requirements of the body. At the same time it is possible that a minimal amount of bicarbonate may be retained on account of renal lesions, just as the ex- 
cretion of sugars and dyes is partially suppressed in certain types of nephritis, even in comparatively mild cases. 'This introduces the possibility that a very minor and, from the standpoint of acidosis, an insignificant proportion of the increase in tolerance is due to renal retention.* Consequently, it is not of vital importance whether one refers to this phenomenon as " a deficit in bicarbonate" as strongly recommended by Palmer and Henderson, ${ }^{23}$ or whether it is called " tolerance to bicarbonate" in the sense that I have described in greater detail in a previous paper. ${ }^{25}$ The expression "tolerance to bicarbonate" has the advantage of uniformity with the nomenclature of other tests in clinical medicine which are analogous to this one; being a general term, it is rather more accurate since it includes any possible minor factors as well as the major factor, "deficit in bicarbonate." All in all, the more general term "tolerance to bicarbonate" is preferable since it is obviously impracticable to describe the exact mechanism of a phenomenon in the few words of a title.

* These data establishing this conclusion are not taken into consideration by Rowntree in his very recent criticism that the alkali tolerance test in renal insufficiency is useless and misleading. ${ }^{14}$ Rowntree also considers that the carbonates are comparable to other substances used in testing renal function, but it must be pointed out again that a fundamental difference exists. As a rule, only partial and very incomplete suppression of substances results from renal insufficiency even after the administration sometimes of very minute amounts; in contrast to this behavior, when substances are stored to make up a deficit in the tissues relatively enormous amounts can be administered often without even a trace appearing in the urine. By way of illustration, ${ }^{24}$ in seven cases of uraemia the administration of 30 to 160 grams of bicarbonate was not followed in any instance by an alkaline urine. In these same cases, 0.6 to 1.2 milligrams of phenolsulphonepthalein and 5 to 10 grams of lactose was not completely retained in any instance. 


\section{RELATIVE VALUE OF THE VARIOUS TESTS FOR ACIDOSIS}

In forming an opinion of the relative value of the laboratory methods for detecting acidosis, it is well to consider the order in which the various tests would appear in the gradual development from normal conditions to a state of advanced acidosis. While no one has worked out the exact sequence, still their relative position is, in general, fairly well known. Minor variations necessarily occur in individual cases and in acidoses of various etiology, yet sufficient data are available for the construction of the following outline, giving the tests in the order of their delicacy:

1. Appearance of acetone bodies in the urine (for carbohydrate acidosis only).

2. Increase in tolerance to sodium bicarbonate.

3. Lowering of the carbon dioxide of the alveolar air and of the blood.

4. Change in reaction to phenolphthalein, from alkaline to neutral, of protein free filtrate from blood serum.

5. Increase in output of ammonia in urine (usually normal in nephritic acidoses).

6. Increase in hydrogen ion concentration of the blood.

The appearance of acetone bodies is, unfortunately, limited to diabetes or to disturbances of the carbohy- 
drate metabolism. Moreover, a slight increase in the normal output of acetone occurs so easily (sometimes with twelve hours fasting) that it does not indicate any depletion of the fixed bases. Furthermore, definite acidosis may develop in diabetes without the appearance of acetoacetic acid in the urine and when the output of acetone and ammonia is within normal limits. There is one precaution which should be observed in the consideration of acidoses due to $\beta$-oxybutyric acid. For example in typical diabetic acidosis the fixed bases become depleted. Then, if the excretion of $\beta$-oxybutyric acid were suddenly stopped by the administration of carbohydrates, the acidosis, i. e., the depletion of the alkali reserve, would persist for some time. The tolerance to bicarbonate would be abnormally high but there would be no acetone in the urine. Thus, in the examination of urine in diabetes, the expression "acetone free" does not necessarily have the same significance as "sugar free." In other words it does not always signify that metabolism is normal and that the patient is necessarily free from acidosis. Evidently, considerable precaution is necessary in drawing conclusions regarding acidosis from the examination of the urine for acetone in diabetes, since the presence of acetone does not establish the existence of acidosis, and its absence by no means proves the absence of acidosis. A similar relationship pertains between the acetone bodies and acidosis in children. This subject has been thoroughly discussed by Howland and Marriott. ${ }^{26}$

In the preceding outline, the position of carbon dioxide in the blood and in the alveolar air is extremely difficult to place, partly on account of its comparatively wide normal range and also because conditions other 
than acidosis may produce a slight lowering of the carbon dioxide. Hence as regards the relative position which the lowering of the carbon dioxide bears to the other tests, it is necessary to decide whether one is to take into account only those changes which are characteristic of acidosis or whether one is to consider also those earlier changes which may likewise be produced by other conditions. Even considering the earliest changes that are definitely demonstrable, the position of carbon dioxide cannot be placed higher than it appears in the preceding list. On the other hand, if one considers only the outspoken changes which would of themselves be absolutely pathogonomonic of acidosis, then its position would be much lower in the scale, perhaps just preceding the change in the hydroxyl ion concentration of the blood.

In developing the method for testing the reaction of the protein free filtrate from the serum with phenolphthalein, I did not attempt to adjust this to its greatest possible delicacy, but rather to use it under conditions in which a change from the normal could be depended upon to indicate acidosis. In its present form, it served to demonstrate that the increase in tolerance to bicarbonate in the nephropathies is essentially a bicarbonate deficit. Without further refinement it is also sufficiently delicate to detect acidosis of any clinical significance. It is not only of diagnostic value but is of considerable help in regard to therapy. Thus it enables one to decide whether the administration of alkalies is advisable and whether the amount required will be sufficiently large to necessitate intravenous injection. Also, when massive doses of alkali are being injected it is only by examination of the blood or alveolar air that one can 
determine when the injections should be diminished in order to avoid overstepping too far the amount required to change the reaction of the urine. The examination of the urine gives practically no warning of the approaching change from an acid to an alkaline reaction.

The study of the excretion of ammonia is not so helpful in the diagnosis of acidosis as was formerly supposed. The ammonia coefficient may be high in primary disturbances of protein metabolism or may be low in outspoken acidoses.

It is not necessary to emphasize further the lack of clinical value of determinations of the changes in the hydrogen ion concentration of the blood for the early detection of acidosis.

The increase in the tolerance to bicarbonate (the " bicarbonate deficit") is the most delicate of the tests which are specific for acidosis. By the use of this test, it was possible to detect:

1. Very slight grades of experimental acidosis in man resulting from two to three days of carbohydrate free diet or from the ingestion of about 2 to 3 grams of dilute hydrochloric acid over a period of four or five days.

2. Moderate grades of acidosis in diabetic cases which show no excess of acetone or ammonia over the normal.

3. Moderate acidosis in comparatively early cases of nephritis.

In cases of early acidosis, this tolerance to bicarbonate showed a definite increase at a time when the blood was still normal as regards its content in carbon dioxide and 
its reaction to phenolphthalein and when the urine did not show any change in its ammonia output and did not give any evidence of the existence of an acidosis. Moreover, when the tolerance to bicarbonate is normal, then acidosis can be excluded.

The choice of clinical tests will of course be influenced in a large measure by circumstances and by the purpose which one has in view. For example the diagnosis of early stages of acidosis in nephritis is a different problem from the regulation of alkaline therapy in advanced diabetic acidosis. Under conditions in which an especially delicate test is required, the determination of the tolerance to bicarbonate is the most suitable procedure. In addition to the delicacy of this determination it combines in one step a measure of the degree of acidosis and an appropriate therapy.

On the other hand, if it is only a question of distinguishing between a well developed acidosis and some other form of dyspnoea or coma, one may wish to avoid the delay of waiting for urine specimens which the tests for tolerance involve. Under such circumstances one may employ either the determination of the carbon dioxide content of the alveolar air or the reaction of the blood serum to phenolphthalein after removal of the protein. The abundance of normal reactions that are obtained is sometimes a little disappointing but this only serves to emphasize the comparative rarity in a general clinic of acidosis possessing clinical significance. For purposes of special study, where a series of observations at frequent intervals is desired, the examination of the alveolar air is the most desirable method in order to avoid the repeated venupuncture necessary for determining the titratable alkalinity or the carbon 
dioxide content of the serum. In the study of comas, specimens of urine may often be difficult to secure and it is only recently that those tests have been developed which render one independent of the examination of the urine in the diagnosis of acidosis.

The depletion of the borly in carbonates and other alkali yielding substances constitutes, in the ultimate analysis, the primary underlying factor in the following tests for acidosis, namely, the change in the carbon dioxide content (1) of the blood and (2) of the alveolar air, (3) the concentration of the blood in hydrogen and hydroxyl ions, (4) the tolerance to fixed bases and (5) the titratable alkalinity of the blood. In establishing, for the first time, the existence of acidosis in a given disease, it is obviously desirable to depend upon not less than two methods; relatively little importance would attach itself to any single test in the preceding list, especially if only a moderate degree of change was found. The presence of acidosis in some of the earlier stages of the nephropathies was proven by demonstrating an increase in tolerance to bicarbonate accompanied by qualitative changes in the reaction of the protein free filtrate of the serum. In uraemia and preuraemic conditions, the occurrence of acidosis was confirmed by establishing that the carbon dioxide content of the blood was very markedly decreased. Peabody ${ }^{27}$ has produced proof of the occurrence of acidosis in uraemia. The crucial tests which were employed by Peabody were the determination of the hydrogen ion concentration of the blood and the carbon dioxide content of the alveolar air. The hydrogen ion concentration of the blood was slightly but distinctly increased in uraemic cases a few days before death and there was a 
corresponding lowering of the carbon dioxide tension of the alveolar air.

The subject of acidosis in cardiorenal disease is discussed in a report by Lewis, Ryffel, Wolf, Cotton and Barcroft. $^{28}$ These authors depended principally upon the determination of the carbon dioxide of the alveolar air. Notwithstanding the extensive series of observations which were conducted, the evidence is somewhat contradictory and has not proven to be convincing as regards the occurrence of acidosis. In a single instance they report a pressure of $24 \mathrm{~mm}$., in a case which they do not consider to be acidosis as compared with a normal range of 36 to $42 \mathrm{~mm}$. Moreover, they found in nine cardiorenal cases, in which they consider that acidosis was present, the tension of carbon dioxide in the alveolar air did not fall below $25 \mathrm{~mm}$., except in one instance; it was frequently over $30 \mathrm{~mm}$. and occasionally as high as $40 \mathrm{~mm}$. These discrepancies are not easily explained and they leave some doubt as to the conclusions which should be drawn in these cases.

Straub and Schlayer ${ }^{29}$ found a definite lowering of the carbon dioxide of the alveolar air in nephritis but they do not draw any final conclusions from their data. Porges and Leimdörfer ${ }^{30}$ observed that the tension of the carbon dioxide in the alveolar air is in general proportional to the symptoms of uraemia. However, as already mentioned, these authors together with Markovici found a similar lowering in decompensated cardiac cases, a condition in which the existence of acidosis has not yet been established. In a later paper, Straub ${ }^{31}$ conforms with the general view that the lowering of the carbon dioxide tension in uraemia represents a form of acidosis. 
In some early work on the titration values of the blood von Jaksch ${ }^{32}$ found some low values in a variety of conditions, more especially in severe fevers (typhoid, pneumonia and sepsis), in anaemia, in cachexias, in diseases of the liver and in leukaemia. Low values occurred almost constantly in uraemia though equally low results were found in a number of other conditions in which subsequent investigations have not demonstrated an acidosis comparable even to that which may occur in mildly uraemic patients. The titration method used by von Jaksch does not merit confidence and his results have not been interpreted as establishing the existence of acidosis in uraemia. 


\section{VI \\ DEFINITION OF ACIDOSIS}

The term acidosis has been used freely in the literature with a considerable variety of meanings and often without any well-defined significance; the variety of interpretations has been so great that, until recent years, the idea of acidosis has been regarded only as a theory. It is now generally accepted that acidosis is essentially an impoverishment of the body in alkalies. This idea was clearly stated by Naunyn ${ }^{33}$ in 1906 under the term hypalkalität and by Emerson ${ }^{34}$ using the expression alkali starvation. This interpretation has received ample support from the investigations of the physicochemical reaction of the blood, the carbon dioxide content of the blood and alveolar air, the titratable alkalinity of the blood and the tolerance of the body to sodium bicarbonate. In its simplest terms, then, acidosis is an impoverishment of the blood and other tissues in fixed bases or in substances which readily give rise to fixed bases. Death takes place before any significant change occurs in the reaction of the blood; it remains alkaline both in its physicochemical reaction and in its behavior to indicators. It will be seen that there are many ways in which this depletion in alkali may be brought about. In diabetes, for example, organic acids instead of being destroyed by oxidation are neutralized by alkalies. In cholera it is probable that a certain amount of fixed alkali is lost by elimination as such from the bowel. This latter type has sometimes been called 
a relative acidosis in contrast to the absolute acidosis of diabetes. The meaning of these terms is extremcly indefinite but there is a distinct implication that in the relative acidosis there is less alkali than normally, while in the absolute there is an excess of acid. This is misleading since in any acidosis there is simply a diminution in the supply of alkali. Accordingly it is difficult to ascribe any useful place to the terms relative and absolute as applied to acidosis. Indeed, the terms acidosis and acid-intoxication themselves are misnomers. Their use came about very naturally in the original experiments where mineral acid was fed to animals through a stomach tube, and subsequently, the same terms were carried over into human pathology. Certainly, a more fortunate expression would have been some word signifying hypo-alkalinity. A particularly misleading term which sometimes appears is the use of the word acidaemia. This arises in part from a complete indifference in distinguishing between acids and their neutral salts. As a result, sodium oxybutyrate or sodium chloride are spoken of as acids in the blood.

There is an expression compensated acidosis which can easily give rise to confusion. Strictly speaking, all normal individuals are in a state of compensated acidosis, i. e., normal metabolism gives rise to an excess of acid radicals which must be either neutralized or excreted. Even in extreme acidosis, the body still compensates in a large measure; the hydrogen ion concentration of the blood rises only a little even at death, whereas, except for the compensating processes of the body, the amount of acid that is produced would cause a relatively enormous rise. From a biochemical standpoint, then, an acidosis is always either completely or partially 
compensated, and there is no wholly uncompensated condition. On a clinical basis, one might divide the cases into compensated and partially compensated groups, according to the presence or absence of clinical symptoms. Such a division would necessarily be rather indefinite. The situation becomes even more difficult if one attempts to distinguish two groups by the measurement of the hydrogen ion concentration of the blood. By such means the two groups of cases could be differentiated neither by their clinical symptoms nor by the ordinary laboratory tests for acidosis, but the distinction would have to be made by physicochemical methods. The transition from complete to partial compensation is extremely gradual and there is no basis on which the cases can be sharply subdivided into distinct groups. For the ordinary descriptions of individual cases it seems sufficient to express the relative severity of the acidosis. If a definite basis for the comparison of different cases is desired the determination of the tolerance to bicarbonate would be much more serviceable than the measurement of the hydrogen ion concentration of the blood.

It does appear especially desirable to limit the term acidosis to those conditions in which systemic change occurs so that the body as a whole shows some systemic abnormality. There is a little tendency of late to consider, as an acidosis, certain sharply localized accumulations of acid. Thus instances may arise of a slight and well localized production of acid in a bacterial focus, or as in Fischer's ${ }^{35}$ tests of the kidney tissue with indicators for acids. But the amount of acid, though it can readily be detected by indicators, is either so small in amount or so sharply localized that it produces no 
measurable effect on the body tissues as a whole or the fluids in general circulation. Such a condition is evidently very different from a partial depletion of the reserve supply of fixed bases and it would be confusing to inchude the two under one name. At the same time, it is obvious that a high grade bacterial infection, especially if it is not localized, might produce sufficient acid to lead directly or indirectly to a measurable depletion of alkalies. 'The distinction between a local and general effect might appear to be a difficult one. Fortunately, however, there are adequate methods which are amply delicate for the detection of any change in the reserve supply of base. However at the commencement of a general depletion, the division between normal and pathologic conditions is entirely quantitative and necessarily somewhat arbitrary. In the selection of the normal standards there is naturally some opportunity for a variation of opinion, but the crucial point is the adoption of suitable tests by which the normal values shall be determined.

In the selection of a standard test for the definition of acidosis, it is practically necessary to choose one which is of general application. This, at once, eliminates the reactions for acetone, acetoacetic and $\beta$ oxybutyric acid, and the determination of ammonia. Likewise the measurement of the hydrogen ion concentration of the blood obviously is inadequate. A fair working basis could be obtained by the determination of the carbon dioxide content of the alveolar air or of the blood, or by the measurement in the change of the titratable alkalinity with phenolphthalein, after the removal of the protein. The changes in the carbon dioxide, however, do not constitute an ideal basis. In 
the first place, the normal variation is fairly wide. Moreover, in formulating the definition of acidosis it is important to consider the body as a whole and not the blood alone. This may be brought out more clearly by referring to other pathologic processes. In a number of instances when the body is becoming impoverished in certain constituents, a fairly normal composition of the blood is maintained at the expense of the other tissues. For example, when a serious diminution occurs in the supply of water or of carbohydrates, the blood is replenished from the other tissues until their supply is seriously depleted. This phenomenon would seem to be a general law, applicable to a number of substances and apparently it holds very well indeed in the case of the fixed bases. Viewed from this standpoint, acidosis is fundamentally a diminution in the supply of fixed bases in the blood and tissues of the entire body and the term should not be limited to the carbonates nor to changes in the blood alone. In the definition of acidosis these limitations may be avoided, at least in a large measure, by the determination of the tolerance to bicarbonate. With this test, definite proof of acidosis was obtained while the tension of carbon dioxide in the blood was still normal. The tolerance tests possess the further advantage that the normal values are relatively constant and the available evidence indicates that the tolerance to bicarbonate is increased only in acidosis.

The interpretation of the values obtained in the bicarbonate determination is very simple since the normal tolerance is constant and low as compared with the values obtained in stages of acidosis that are of any clinical significance. Five grams of sodium bicarbonate by mouth is practically the upper limit of normal toler- 
ance, this quantity being almost invariably sufficient, in a normal individual, to change the reaction of the urine from acid to alkaline. A tolerance of ten grams could logically be considered as an acidosis, but such a slight increase could not have any clinical significance since the tolerance may be several times as great as this without the appearance of clinical symptoms.

Acidosis, therefore, may be very simply and correctly defined as a diminution in the reserve supply of fixed bases in the blood and other tissues of the body, the physiochemical reaction of the blood remaining unchanged except in very extreme conditions. The definition should not be limited to the carbonates alone but should include the other fixed bases of the body; likewise, the changes should not be limited to the blood but should include the other tissues as well. The subdivision of acidoses into compensated and uncompensated and into relative and absolute types is not particularly logical nor helpful. Sharply localized accumulations of acid which do not produce any systemic effect should, at least, be carefully distinguished from generalized metabolic disturbances and preferably they should not be considered as an acidosis.

The transition from the normal to a state of acidosis is quantitative rather than qualitative in its character. By virtue of the physiological constancy of the reserve supply of fixed bases this transition may be readily detected by determining the tolerance to bicarbonate. 


\section{VII}

\section{OCCURRENCE OF ACIDOSIS}

In considering the occurrence of acidosis, it is advantageous to separate the conditions in which it appears into two groups, namely, (1) those diseases in which it may become sufficiently marked to produce definite clinical symptoms, and (2) those conditions in which it is so mild that it can be detected only by laboratory procedures. Such a division at once segregates the miscellaneous group of cases in which definite but inconsequential signs occur. The diseases, in which the development of clinical symptoms is characteristic, are few in number; for many years it was assumed that all forms depended, in their ultimate analysis, upon a disturbance of the carbohydrate metabolism. As recently as 1907, von Noorden pointed out that it is only in diabetes that definite acidosis has been established. At this time the possibility of acidosis in nephritis had only been suggested even in the stage of uraemia, except in so far as a slight starvation acidosis might appear. Recently, however, it has been established that extreme acidosis may develop, not only in nephritis, but also in one other condition: Howland and Marriott ${ }^{36}$ have proven that a typical and often fatal form develops in some of the so-called food intoxications of children.

In the nephropathies, it is important to note that acidosis does not occur in all types of kidney lesions. In the frankly parenchymatous type, no evidence of acidosis has been obtained. Likewise, in the early stages of the chronic interstitial and arteriosclerotic 
types, the signs of acidosis are lacking, but they develop in proportion as the lesions progress, becoming very pronounced in the stage of uraemia. Indeed, before the development of uraemia, an advanced acidosis usually appears in cases of chronic diffuse nephritis, in primarily contracted kidneys, and in the acute nephritides. As far as we know at present, one would cxpect definite acidosis in any case of infectious disease in which a severe acute nephritis develops. The one most striking instance, however, is Asiatic cholera, for there is no other infection in which critical renal lesions develop in such a high percentage of cases.

Very typical clinical signs of acidosis may develop in one other condition, namely, in advanced lesions of the liver, more especially in the atrophic cirrhoses. These cases, at least those which present symptoms of acidosis, are not very common and they have been studied but very little.

It is often considered that acidosis frequently accompanies febrile conditions. Fridericia and Olsen ${ }^{37}$ from the examination of the alveolar air have reported moderate lowering of the carbon dioxide tension. In a case of erysipelas with a temperature of $38.9^{\circ} \mathrm{C}$., values as low as 31 millimeters were found; occasionally, though, in this and other infections the lowering was by no means constant. These results, though suggestive, can hardly be accepted as proof of acidosis without the confirmatory evidence of other methods; in any case it would seem to be a rather inconstant phenomenon. Of the febrile conditions studied by Walker and Frothingham ${ }^{15}$ the most definite lowering occurred in acute rheumatic fever, a condition in which there are other definite evidences of acidosis. 
Barcroft ${ }^{38}$ finding a diminution in the carbon dioxide of the alveolar air at high altitudes assumes that there is also a diminution of carbonates in the blood. This indication of acidosis was supplemented by titrating whole blood with standard acid till the haemoglobin began to precipitate using this reaction as an end point. The relationship of these changes to acidosis is not yet fully determined.

Considerable attention has been directed to the study of acidosis in recent years. However, one would hardly expect to find many more diseases in which typical fatal acidosis develops as a common occurrence. A survey of the long list of diseases prevalent in the tropics fails to reveal any additional conditions which might be expected to reveal a significant degree of acidosis, except as it is associated with secondary anaemias and the acute nephritides. Even severe anaemias have not yet been shown to produce acidosis of high grade. Since the clinical symptoms of advanced cases are so easily recognizable, it would seem unlikely that any extreme conditions had been overlooked, even when masked by complicating factors. Indeed in the nephropathies and in the diseases of children, the possibility of acidosis had been suspected for a long period, on account of the clinical symptoms. These cases did not conform, however, to the ordinary diabetic acidosis and it has been necessary to develop new laboratory methods for the final establishment of the existence of acidosis in them. Although there are no indications that any outspoken acidoses have escaped attention, the possibility remains that somewhat different forms may yet be discovered. For example, there is very little evidence, at present, as to the effect of a long- 
standing moderate grade of acidosis. It is not inconceivable that an extremely chronic acidosis, while of no consequence per se, might, nevertheless, constitute a predisposing factor in association, for example, with other disturbances of nutrition.*

The milder grades of acidosis may develop and persist for a short time in a variety of conditions though there is apparently a tendency both among clinical and laboratory workers to exaggerate the ease with which slight acidosis may occur. Thus, in the wards of an ordinary general clinic, one would not expect to find cases with an increase in soda tolerance to even twenty or thirty grams, except in certain fairly well recognized conditions. One should mention, more especially, acute rheumatic fever, advanced cachexias and severe anaemias. Preliminary investigations, however, indicate that acidosis does not develop in more than perhaps one-fifth of the severe primary and secondary anaemias, and even then it is usually of very low grade, the tolerance to bicarbonate seldom being more than twenty or thirty grams.

At present, several workers are investigating the possibility that acidosis may play some role in the untoward symptoms following general anaesthesia. Crile, ${ }^{40}$ in his views concerning the increase in the acidity of the blood in anesthesia, in emotional states and in exertion, departs widely and radically from the accepted teachings of the theory of neutrality regulation.

The occurrence of acidosis in renal and cardiorenal disease has naturally led to an attempt to explain in this

* During the course of investigations relating to this subject Steenbock, Nelson and Hart ${ }^{39}$ draw the lentatative conclusion " that natural acid rations, if otherwise satisfactory, are as effective for growth or reproduction as those of basic character." 
way the dyspnoea of pure cardiac cases. Porges, Leimdörfer and Markovici ${ }^{18}$ found a low carbon dioxide content of the alveolar air in uncomplicated cardiac cases. This evidence is suggestive but it is not supported by other tests for acidosis. Peters ${ }^{70}$ has found an unusual discrepancy in the relationship between the carbon dioxide content of the alveolar air and the venous blood, the alveolar air showing a low content in contrast to the high values found in the blood. In my own work, four completely decompensated cardiac cases showed no change in the reaction of their serum to phenolphthalein. The evidence at hand does not point toward the existence of acidosis in uncomplicated cardiac cases. 


\section{VIII}

\section{THERAPY}

As regards the therapy of acidosis, it is intended to consider here only the use of alkalies, though obviously the ideal treatment would consist in removing the cause of the acidosis. At first thought, it would seem plausible to suppose that the relief of symptoms in diabetic coma, which follows the injection of massive doses of alkali, is due to neutralization of acid. On the contrary, however, no free acid is present and the injected alkali is stored as such in the body. The symptom of air hunger is due not to the presence of acid but to the loss of carbonates from the body. The injected carbonates relieve air hunger only in so far as they persist in the body as carbonates and function as such in carrying carbon dioxide. If they are neutralized shortly after injection by newly formed acid, then the relief of symptoms does not occur, or, at most, is only very transient.*

The general effect of alkalies in the acidosis of diabetic coma has been studied clinically over a long period of years and the behavior of these cases is well understood. The acidosis of renal disease arises in a different manner from that of diabetes; though the condition

* Confusion on this point might readily arise from von Noorden's discussion of the subject; in his monograph on acid-intoxication the administration of alkalies is advised in diabetic acidosis in order to combine with the acids, to disintoxicate the poisonous acids and to prevent their accumulation in the blood..$^{5 \mathrm{~b}}$. This impression however is partially corrected in other portions of the monograph in which it is emphasized that $\beta$-oxybutyric acid is non-toxic and produces its effects by virtue of its acid character. ${ }^{510}$ 
is fundamentally the same in its general principles, there is a distinct difference between the nephritic and diabetic cases as regards their response toward alkaline therapy.

The question of the advisability of treating the acidosis of nephritis is a somewhat complicated subject, and it will be simpler to consider the acute and chronic types separately. For the study of acute nephritis there is no infectious disease which furnishes such an important opportunity as Asiatic cholera. The percentage of fatal cases of uraemia is not only very high (average 15 per cent) but they occur with considerable regularity. Moreover, acute nephritis develops in practically all severe cases which live till the stage of reaction is reached. One has, therefore, the opportunity to study the effect of prophylactic measures before the onset of nephritis, and of therapeutic measures in the stage of acute nephritis and in uraemia. In certain respects, therefore, the conditions are almost ideal for a crucial clinical test of the therapeutic value of alkalies. The disappointing results of the treatment of acidosis as it occurs in the temperate zones has been advanced from time to time as an argument against the theory of acidosis and has been a source of delay in the development and acceptance of this theory. Indeed it is so rare to obtain permanent benefit that it seems worth while to consider the treatment of the acidosis of cholera in some detail.

The effect of massive doses of bicarbonate was tested by myself in a small epidemic of cholera occurring in Manila. ${ }^{21}$ In the study of 193 cases, 111 of which received special treatment, satisfactory evidence was obtained that fatal uraemia could be prevented provided 
injections of alkali were commenced either during the stage of collapse, or even after an outspoken nephritis had developed, but before a typical uraemia had appeared. In a subsequent epidemic comprising a study of only 44 cases, a similar result was obtained. The cases of the two epidemics were divided into two parallel series in which one group received alkaline therapy, and the other, neutral salt solution. The final results obtained in the two epidemics were as follows:

\begin{tabular}{c|c|c|c|c}
\hline \multicolumn{1}{c|}{ Treatment } & $\begin{array}{c}\text { No. of } \\
\text { cases }\end{array}$ & $\begin{array}{c}\text { Deaths in } \\
\text { uraemia }\end{array}$ & $\begin{array}{c}\text { Total no. } \\
\text { of deaths }\end{array}$ & $\begin{array}{c}\text { Total no. } \\
\text { recoveries }\end{array}$ \\
\hline Neutral Solution........ & 78 & 12 & 49 & 29 \\
Bicarbonate (or Acetate). & 77 & $1^{*}$ & 32 & 45 \\
\hline
\end{tabular}

The conclusions in regard to the elimination of uraemia, as a cause of death by the use of bicarbonate, are not based upon the percentages in the preceding outline but upon the change in the course of the disease produced by alkaline therapy. Patients receiving bicarbonate during the period of collapse did not develop severe uraemia during the stage of reaction.

Patients admitted in the period of reaction, even though they had had complete suppression of urine for several days, voided freely after massive injections of bicarbonate. Such patients sometimes made an unin-

* This was an apparently mild case. No bicarbonate was given on admission but 30 grams of sodium acetate were injected - an inadequate amount of alkali yielding salt. The unusually high death rate in this group from collapse is due chiefly to the large number of cases admitted in an almost moribund condition in the first epidemic. In the second epidemic, of the $2 \&$ cases treated with alkali, there were 4 deaths from collapse and none from uraemia; of the same number treated with Ringer's solution there were 5 deaths from collapse and 4 with definite signs of uraemia. 
terrupted recovery; those who succumbed did not die of uraemia. Patients admitted in advanced uraemia with complete suppression of urine voided freely after liberal injections of bicarbonate but none of these cases recovered. They usually lived several days, becoming much clearer mentally and resting much more comfortably than under morphine treatment.

Some of the individual cases were of especial interest. One patient was admitted after an illness of two and a half days. The symptoms of the stage of collapse, such as the cyanosis, the quick shallow respiration, the low blood pressure with a rapid, feeble pulse and the diarrhoea, had been replaced by the characteristic signs of the stage of reaction. The cheeks were flushed and the mucous membranes were bright pink in color; respiration was natural. The pulse was full and bounding, the blood pressure measuring 175 millimeters of mercury. Constipation had already set in. The suppression of urine had been complete since the onset of the disease. Thirty grams of sodium bicarbonate were injected intravenously, the tension of the pulse diminished and after ten hours the blood pressure had fallen to $\mathbf{1 3 5}$ millimeters of mercury. Sixteen hours after the injection, the secretion of urine commenced. Without the use of any additional bicarbonate, the amount of urine increased rapidly and a prompt recovery followed.

In another case, anuria had persisted for three days. Secretion of urine finally commenced eighteen hours after several injections of bicarbonate, amounting in all to ninety grams. The lesions of the kidney were so advanced that the normal pigments were entirely suppressed when the first specimen of urine was passed, the sample being water-clear. A second specimen a few 
hours later contained a trace of pigment and the third specimen was straw-colored. This patient made an uninterrupted recovery without any additional injections.

In ascribing these results to the effect of bicarbonate, the most pertinent question that suggests itself is whether the anuria of these cases would not have yielded to injections of neutral salt solution or other therapy. The striking eharacteristic of these cases is that although the anuria may yield spontaneously, there is no form of therapy which can be depended upon to start the secretion of urine. Injection of neutral fluid can be continued till oedema of the base of the lungs sets in, without any urine being secreted. The effect of bicarbonate is therefore very striking since at practically any period during the stage of reaction or even of uraemia, massive injections will cause a secretion of urine. Moreover, a polyuria often develops promptly in contrast to the scanty secretion of the cases treated with normal saline. Furthermore, there was only one instance in which complete suppression of urine for a period of two days did not eventually prove to be fatal in the series treated with salt solution, whereas seven cases under alkaline therapy recovered after an anuria of two days' duration; in a single instance recovery took place after three days of total suppression.

This therapeutic action has also been confirmed in a large measure by Rogers and Shorten. ${ }^{41}$ In a series of 225 cases, treated in 1915 with alkalies, the death rate from uraemia was 2.7 per cent, as compared with 11 per cent in 1914, 8.5 per cent in 1913 and 14 per cent in 1912. Massive injections of bicarbonate were used, 10 to 96 grams as a rule (160 to 1440 grains), and in one case about 150 grams (2240 grains). The reaction of 
the urine is not reported. The observation, therefore, that the urine remains acid after large injections of alkali remains unconfirmed. One would like to think that the urine remained acid in all of these patients but this is not probable in view of the results obtained in Manila. These cases, however, do support the conclusions regarding the clinical effect of bicarbonate, notwithstanding the fact that several cases died in uraemia. Three of these are readily explained since they were admitted in uraemia. As regards the others, the treatment followed by Rogers and Shorten differs in several important respects from that which was employed in my own series. The main points of difference are as follows:

1. The injection of bicarbonate was begun later in the course of the disease, patients admitted in collapse receiving first a hypertonic solution of sodium chloride. The subsequent injections consisted first of a strong solution of sodium bicarbonate 2 per cent, and sodium chloride followed by a hypertonic solution of sodium chloride. In contrast to this regime it is preferable to begin with prophylactic injections of alkali before the symptoms of acidosis appear. As was shown by Shaklee and myself ${ }^{42}$ the stage of collapse can be handled very satisfactorily with a one-half per cent solution of bicarbonate made isotonic with Ringer's solution, in as far as the presence of bicarbonates will permit the calcium to remain in solution. This is theoretically and practically an improvement on the use of hypertonic sodium chloride. McLaughlin and myself ${ }^{43}$ found no value in the use of hypertonic sodium chloride solutions in the treatment of cholera as compared with normal saline.

2. In the stage of reaction larger injections of bicarbonate should be used omitting the sodium chloride. 
The practice of flooding the body with a large excess of sodium ions is not to be commended.

3. 'The injection of bicarbonate frecly into the blood stream is not permissible unless the reaction of the urine is recorded. Observations on the blood are valuable but they are not sufficiently accurate to determine the point at which the injection of bicarbonate must be discontinued. It is not permissible to use massive injections of alkali intravenously after the urine has become alkaline.

It should be noted that Rogers does not stand alone in his recommendation of the use of sodium salts only. Wherry ${ }^{44}$ likewise recommends a rather concentrated alkaline solution composed of the chloride and carbonate of sodium for the treatment of cholera. The importance of calcium salts and the value of a proper balance of the various salts in the blood has been adequately established. Busquet and Pachon ${ }^{45}$ found that salts which precipitate calcium are deleterious in their action on the heart. Loeb ${ }^{46}$ showed that the precipitation of calcium salts gives rise to muscular tremors and twitchings. The important relationship between calcium salts and tetany has been established by MacCallum ${ }^{47}$ and his associates. Accordingly it seems advisable to employ calcium and avoid too great an excess of sodium in the treatment of cholera.

The rôle of acidosis in cases of acute nephritis occurring in the temperate zone has been studied very little indeed. It is entirely reasonable to suppose that therapy with alkalies, if it is commenced sufficiently early, would tide these patients over the period of grave renal crisis. In many instances, however, the original cause of the renal lesions, e.g., the septicaemias of Micrococcus 
lenta, would persist with serious manifestations in contrast to the promptness with which many patients recover from infection with cholera.

The effect of prophylactic measures and the therapy of acute nephritis is naturally much more hopeful than the treatment of advanced chronic conditions. The action of alkalies in chronic nephritis was tested upon some cases occurring in Baltimore. In a few cases of uraemia developing in the course of a long-standing diffuse nephritis, a definite clinical effect was produced by massive injections of bicarbonate, as much as 160 grams being used in one instance. The air hunger was partially relieved, the coma diminished, patients were made distinctly more comfortable, and in some instances, the secretion of urine improved. The relief, however, was only partial and was very transitory, lasting not more than two or three days. In two cases which may be designated as preuraemic, the mental condition cleared up promptly after injection, the dyspnoea disappeared and the patients remained in good condition during the few succeeding weeks in which they were under observation before discharge from the hospital. There was still another case in which the behavior proved to be instructive. This patient when at rest in bed had slight dyspnoea and though perfectly clear he became fatigued mentally rather easily. This case received 120 grams of bicarbonate intravenously; his respiration became natural and mentally he became distinctly more alert. He also noticed this change and expressed some surprise at his previous apathy.

Even in fatal uraemia alkali therapy is of value, in that it is the only agent that will relieve air hunger and also it is more effective than morphine in controlling restlessness. 
It is hardly necessary to caution against the interpretation that all dyspnoca of renal disease could be relieved by therapy with alkalies. Chronic nephritis becomes such a complicated picture that simple air hunger in uraemia is perhaps the exccption rather than the rule.

Coming now to the earlier cases of chronie interstitial nephritis, without any symptoms of acidosis, it will be seen that the determination of the clinical effect of relieving this acidosis is naturally a very difficult problem. Perhaps the best way of approach would be to follow large groups of cases over a long period of years. Unfortunately, there are no clear data available in regard to whether a long-standing chronic acidosis would have any effect upon general health, upon metabolism and, more particularly, upon the progress of the renal lesions. It is not impossible that the early attention to acidosis might have a favorable influence on the course of the nephritis. The findings in chronic nephritis, in acute nephritis, and in uraemia would fully justify one in investigating the effect of relieving the earlier stages of acidosis. This would involve the administration of moderate quantities of bicarbonate, a procedure which is not objectionable even in nephritis when we consider the importance of these salts in normal metabolism for the function of internal respiration. The necessity of this function is best illustrated by observing the effect of the gradual removal of the carbonates from the body. Data upon man were obtained by observing the effect of varying degrees of depletion of bicarbonate that occur spontaneously in chronic nephritis, i. e., the clinical symptoms in a group of cases were studied and the degree of depletion was subsequently measured by deter- 
mining the tolerance to bicarbonate. In patients who were not taking active exercise a deficit of even 40 or 50 grams of sodium bicarbonate was not accompanied by any clinical signs. ${ }^{*}$ This constitutes a moderately wide margin of safety in the supply of bases which the body possesses. With a deficit of 75 to 100 grams distinct dyspnoea was observed in patients, sometimes after very moderate exercise and even in cases at rest in bed. An individual with a deficit of 110 grams exhibited in addition to dyspnoea a moderate degree of mental confusion. As the tolerance rose to a deficit of 150 to 200 grams, patients developed uraemia with definite air hunger and coma. A deficit beyond 200 grams of bicarbonate is usually followed comparatively soon by death. Apparently life is able to continue for a time with only a minimal amount of fixed bases in the blood. Accordingly it appears that the adult possesses not very much more than 200 grams of sodium bicarbonate or its equivalent in a form available for the function of respiration. In other words the total supply is at least a figure of that order of magnitude.

The treatment of these cases relieved, in part at least, some of the supposedly toxic symptoms of uraemia, namely, the dyspnoea and the mental confusion. Thus it is seen that at least part of the picture of uraemia is due, not to the presence of a foreign toxin, but to the loss of a normal constituent of the blood and tissues. In the practice of bleeding for the relief of uraemia, it must be remembered that, if this procedure removes

* If one accepts Fischer's theories of nephritis then the albuminuria of these cases might be considered as one of the signs of this deficit of bicarbonate. If this discussion the only clinical signs under consideration are the respiration, the color of the mucous membranes and the mental condition, i. e., the generally accepted clinical evidences of acidosis. 
toxins in the blood, it also depletes the body still further in the carbonates which are already seriously reduced. 'This disadvantage, of course, could be readily remedied by injection of carbonates.

In conclusion we may note that the depletion in alkalies occurs comparatively early in chronic interstitial and diffuse nephritis. If it is unchecked, it goes on to the point where it produces marked discomfort to the patient, and eventually, it sometimes becomes the immediate cause of death. If we postpone treatment until clinical symptoms of uraemia appear, then it may requirc comparatively heroic intravenous injections to reduce the acidosis, whereas, this can be easily accomplished in the early stages by the ingestion of a little bicarbonate. One hopeful point in the treatment is that, in contrast to diabetes, the effect of a course of bicarbonate therapy in the acidosis of nephritis was shown to last for a comparatively long time, even weeks or months. Thus in general, it would seem plausible to make a practice of occasionally giving sufficient alkali by mouth to bring the urine down to a reaction that is neutral or alkaline to litmus. A priori, it would seem inadvisable to keep the urine constantly alkaline. Certainly it seems logical to assume that the maintenance of the carbonate content of the body at its normal level would not have any unfavorable effect. Moreover, in the injection of massive doses of bicarbonate in uraemia (150 grams in 40 hours), no effect was seen in regard to oedema. In cases where oedema was present previous to the injection, the amount of the oedema was neither increased nor diminished; in cases without oedema, none was produced by the injection. This result is not in agreement with Fischer's theories of the cau- 
sation of oedema by acids and its relief by alkaline therapy.

In contrast to this difficulty of determining the clinical effect of alkaline therapy in early chronic cases, it is extremely easy to detect the immediate change produced in the blood and urine by the injection of alkalies. Thus with massive injections, the carbon dioxide tension of the alveolar air rises rapidly. Likewise the titratable alkalinity and the carbon dioxide content of the blood increase rapidly. When these factors have been rendered normal, a small additional injection of bicarbonate will render the urine alkaline. In nephritic cases with suppression, the total volume of the urine often increases remarkably. In diabetic acidosis the ammonia output falls rapidly but the excretion of acetone and the "acetone bodies" continues and often increases owing to the flushing out of the tissues. Fortunately for clinical purposes, it is not at all necessary to control the administration of bicarbonate by the determination of all of these factors. In view of the demonstration that alkali is excreted readily, even in advanced renal disease, it is sufficient to observe the reaction of the urine to litmus.

Fischer has recommended the use of large quantities of sodium carbonate and sodium chloride to be given in all forms of nephritis until there is improvement in clinical symptoms. Hogan and others, acting on this advice, have reported favorable results..5 Subsequently, Fischer ${ }^{48}$ has modified this suggestion recommending that the carbonate be given only until the urine becomes persistently neutral to litmus. This modification would eliminate many, if not all, of the frankly parenchymatous cases from treatment by alkali, 
since they often respond with an alkaline urine after a small dose of alkali. Very unfortunately, in the cases cited by Fischer, ${ }^{35}$ no data are given in regard to the reaction of the urine; consequently, one is left in doubt as to whether these patients retained the carbonate for use in the body or whether it was promptly excreted. This information would be especially interesting in the eclamptic cases, since no one has yet reported definite evidence that there is a diminution of alkalies in the blood of eclamptics or that there is any indication for therapeutic injection of alkalies. It seems especially important to avoid the free use of alkalies in the frankly parenchymatous types of nephritis since these patients are prone to react rather violently to even small doses (10 grams) of bicarbonate. Likewise the use of large quantities of alkalies is not permissible except in those cases where it is definitely known that a marked deficit of carbonate exists. This is a requirement that is extremely simple to fulfill. In the early cases it is entirely justifiable to administer 5 grams of sodium bicarbonate by mouth repeating this dose every two or three hours till the urine becomes alkaline.

Also, it seems necessary to caution against the unrestricted use of the normal carbonate. A spurious idea has gained access to the literature that the normal carbonate is much more effective in relieving acidosis than the bicarbonate.* Two reasons are assigned for this, namely, (1) that the carbonate has greater neutralizing

* It is hardly necessary to call attention to the fact that neither the carbonate nor bicarbonate are alkalies. Normal sodium carbonate is the neutral salt of carbonic acid comparable to sodium sulphate or chloride. However it differs markedly from these in one respect; on solution in water, the carbonate breaks up and gives rise to alkali through dissociation of the water. Sodium chloride, being the salt of a very strong acid, cannot produce this effect. 
power than the bicarbonate and (2) that it can take up additional carbon dioxide whereas the bicarbonate cannot. Gram for gram, the carbonate neutralizes much more acid than the bicarbonate (1.6 times as much). However, one can safely use a much stronger solution of bicarbonate than of the caustic carbonate. 'The total amount of alkali which can be administered is limited, in the first place, by the amount of fluid which can be injected, and secondly, by the toxicity of the alkali that is used. This is very great for the caustic carbonate as compared with the bicarbonate. Thus one can use a dosage of the bicarbonate several times greater than one could employ of the carbonate with impunity. This at once outweighs any advantage of the greater neutralizing property of the normal carbonate.

As regards the inability of the bicarbonate to take up more carbon dioxide, this is only an apparent disadvantage. In the lungs, the bicarbonate breaks up promptly, giving off carbon dioxide, and then the resulting carbonate is able to take up carbon dioxide from the tissues. The use of bicarbonate not only affords the body a convenient source of normal carbonate which it can use readily, but it very conceivably furnishes it in the form of a reserve supply which it can draw upon and convert, only as rapidly as it is needed, to the normal carbonate. With proper precautions the administration of alkalies is not attended by danger or disadvantage. In contrast to the view expressed by Joslin ${ }^{71}$ it seems to me that the replacement of alkalies in acidosis is a necessary step corresponding to the maintenance of a proper supply of food and liquid.

The investigations of Howland and Marriott show that the therapy of the acidosis of infantile food intoxi- 
cation agrees closely with the general effects of the treatment of acidosis in nephritis and in diabetes. Symptomatic relief may usually be obtained in the severest cases, but this relief is only temporary except in an occasional brilliant instance in which prompt recovery has been obtained by the injection of bicarbonate. The early treatment of incipient cases, however, before the attack is fully developed offers much more hope. Early in the development of the subject of acidosis in children Edsall ${ }^{49}$ directed attention to the question of therapy. By the liberal use of alkalies, impending attacks were avoided and the acute underlying symptoms subsided of themselves in a few days.

The simplicity of the theory of acidosis and the brilliancy of the effect of treatment in experimental animals led to the hope of similar results in clinical medicine. However, the merely transitory relief which follows the treatment of advanced stages is a very discouraging feature. This failure in therapy appears, at first glance, a little paradoxical. Yet it is obvious that spontaneous cases in man may be accompanied by fundamental differences from the acidosis produced in rabbits by the ingestion of mineral acid. The precise nature of these differences has not yet been carefully defined. In diabetes, the failure of therapy is advanced as one of the arguments that the coma is by no means due solely to acidosis. This view receives support from the apparent occurrence of diabetic coma in patients who are free from acidosis. One hopeful point in therapy consists in the suggestion of Marriott and Howland ${ }^{50}$ as to the possible relationship in uraemia of the deficiency of calcium salts and the occurrence of convulsions. In 
two cases of typical ureamia Peabody found that definite though temporary cessation of muscular twitchings occurred after the intravenous injection of calcium chloride. These preliminary results were sufficiently suggestive to justify further observations along this line.*

It should be remembered that the loss of carbonates is accompanied by a simultaneous depletion of calcium, magnesium, sodium and potassium salts. In treatment, the tendency for the most part is to replace only the sodium and the carbonates. Perhaps some of the symptoms are due to the loss of calcium, magnesium and potassium salts. Von Noorden ${ }^{51 a}$ does not admit that calcium plays any specific part in acidosis but recommends its administration in long standing cases of acidosis.

Osborne, Mendel and Ferry ${ }^{52}$ by varying the salt content of the diet produced some extremely interesting results which may prove to have very direct bearing on acidosis. Rats which were fed on a diet poor in salts but otherwise satisfactory eventually developed coma. They were resuscitated by the administration of a mixture of salts consisting of calcium and potassium phosphates, sodium chloride and the citrates of sodium, magnesium, calcium, and iron.

* Peabody. Personal communication. 


\section{DIFFEREN'TIAL DIAGNOSIS}

Although acidosis, in the majority of instances, is not of primary importance either in etiology or therapy, nevertheless, it is sometimes of considerable interest in differential diagnosis. The infrequency of acidosis in parenchymatous nephritis, as compared with chronic diffuse types, renders it of value in the study of the nephritides themselves. Indeed, the degree of acidosis is of very definite value as a test of renal function. It constitutes a very satisfactory and very direct test of the ability of the kidney to excrete an acid urine, one of the several cardinal functions of this organ. Moreover, except in parenchymatous nephritis the property of excreting acid constitutes a very good index of the general state of the other functions of the kidney. In this connection it is interesting that the tolerance to bicarbonate frequently parallels in a very general way the ability to excrete phenolsulphonephthalein. In an early paper, ${ }^{22}$ the tests for tolerance to bicarbonate were looked upon as being much less delicate than the phenolsulphonephthalein tests. This interpretation was made at the time when the authors of the 'phthalein test considered it to be almost infallible. Since then it has been recognized that parenchymatous cases, even though severe, usually have a high output of this and other dyes; on the other hand, some mild nephritides on a single test will show a low output although the renal function, as far as its natural duties are concerned, 
is nearly normal. The determination of the tolerance to bicarbonate has one distinct advantage over the artificial tests in that it constitutes one of the natural functions of the kidney in maintaining normal metabolism, whereas the ability to excrete foreign dyes bears only an accidental relation to the ordinary functions of this organ. The continuous separation of an acid urine by the kidney from an alkaline plasma is of considerable consequence to the organism as a whole and the determination of the tolerance to bicarbonate constitutes a very satisfactory test of this function.

The detection of acidosis facilitates considerably the prompt differentiation of diabetic and uraemic coma from other types and also renders substantial assistance in the detailed investigation of the diseases of the heart, brain and kidneys. In considering the very complex pictures resulting from lesions of these organs, it is often inadvisable to attempt a sharp definition of the exact extent to which the various organs are affected. It is sufficient to determine whether the essential feature is a lesion affecting primarily the heart, brain or kidney, or whether the picture is a composite one in which no one factor predominates. It might seem that the general division of these cases could be made most appropriately on clinical grounds without the aid of laboratory methods. Even in the cases which clinically appear to be very clear, there is, however, the possibility, at times, of making a striking error in diagnosis, at least temporarily. Under emergency conditions, the laboratory tests may be of value; this is especially true in cases where a history is unavailable and when there has been no opportunity for obtaining a series of clinical observations. As an illustration of such an instance a 
man, age 45 , was admitted to the clinic in coma, with almost complete suppression of urine. No history was available except that the coma was of twelve hours' duration and the patient had been given a diagnosis of chronic nephritis eighteen years previously. On catheterization a few drops of urine were obtained; this specimen showed a variety of casts and a moderate amount of albumin. A liberal secretion of urine started within twelve hours. 'The casts diminished in number and only a trace of albumin remained. On admission, an examination of the blood serum with phenolphthalein showed no evidence of even a mild acidosis and there was no increase in rest nitrogen. The subsequent clinical developments confirmed the tentative laboratory conclusion that this was not a case of uraemia. The coma persisted for four days and then cleared up very gradually in the course of the next ten days, with paralysis persisting in the right arm. During this period, the kidney was functioning very well indeed, the evidence indicating that there was only a mild degree of nephritis. It eventually became clear that there had been a cerebral hemorrhage.

As a further illustration of this discussion, a patient with a marked mitral insufficiency and slight renal involvement, complained of serious dyspnoea which, at times, resembled air hunger. The heart was compensating well, and although renal involvement did not appear to be especially serious, the possibility of uraemia was considered on account of the dyspnoea. There was no acidosis present in this case and the dyspnoea eventually proved to be of neurotic origin.

For a thorough study of these cardiorenal and cerebral cases, it seems not unlikely that a careful examina- 
tion of the blood and urine with respect to renal function and acidosis might furnish useful information. Indeed it would be desirable to obtain extensive data on the occurrence of acidosis in uraemia; although the degree varies considerably, nevertheless, in my own cases and in those of Peabody ${ }^{27}$ at least a moderate grade was constantly present. Although the entire number of patients studied is not large it seems unlikely that any considerable number of instances would be found in which no acidosis occurs. In studying this question, it might be emphasized that in special cases there is opportunity for considerable divergence of opinion in the clinical diagnosis of uraemia. 


\section{$\mathrm{X}$ \\ E'TIOLOGY OF ACIDOSIS}

In explanation of the manner in which acidosis arises, two distinct causes are known, namely, defective oxidation of organic acids and defective elimination of the mineral acids. The best example of defective oxidation occurs in diabetes while the nephropathies comprise the group of defective elimination. In diabetes Magnus-Levy ${ }^{53}$ has insisted that there is no increased production of acids but rather an increased accumulation. In other words the body normally forms a large quantity of acid and oxidizes it immediately; in diabetic acidosis only the normal amounts of acid are formed but instead of being at once oxidized they are allowed to accumulate. A more correct statement would be that there is neither an increased production nor an increased accumulation of acid but that in health, the acid is removed by oxidation and eliminated as carbon dioxide from the lungs, whereas in diabetic acidosis, it is removed by neutralization and elimination from the kidneys.

In the nephropathies, although no disturbance of oxidation develops, still there is no doubt that the loss of alkalies is due to neutralization by acid. The source of this acid, however, is not clear. New acids might be appearing in the urine or the acids normally present might be increased in amount. From the evidence which is available at present, there is no need to assume 
an increase in the amount of normal acids or the appearance of a new acid in metabolism in nephritis. Indeed, on the other hand, Henderson and Palmer ${ }^{54}$ have even reported a diminution of the acidity of the urine in certain severe cases. The same result has been obtained by Peabody. ${ }^{27}$ This would explain, in a large measure, the depletion of the blood and tissues in alkalies. It becomes necessary to abandon the view of von Noorden ${ }^{\text {sld }}$ that diminished elimination of acid is not of practical significance in the production of acidosis. Thus, the normal kidney possesses the rather striking function of excreting acids in the urine. With the development of nephritis and general impairment of kidney function, it is only natural that the function of excreting acid should suffer also, with the result that acid radicals, which are ordinarily eliminated in the urine, would now neutralize fixed bases of the blood before elimination occurs. This view, that the acidosis results from an impairment of the kidney function, is supported rather strongly by several facts. In the first place, the degree of acidosis is, in general, parallel to the other signs of defective excretion as measured by the elimination especially of sugars and dyes, even to the extent of the suppression of the normal pigments of the urine. In chronic nephritis, acidosis develops only gradually, and in contrast to diabetes, it does not reach a high grade as long as the excretion of acid by the kidney is comparatively efficient. Even in high grades of acidosis, the effect of the injection of carbonates lasts for a comparatively long time. In any case, therefore, whether the acid in nephritis is a new product or one of the normal acids, it is not produced rapidly and its neutral salt does not accumulate in large quantities. 
More direct evidence of the deficient elimination of acids by the kidney in nephritis has recently been brought forth by Marriott and Howland ${ }^{50}$ who showed that the inorganic phosphates of the blood are increased in those cases of nephritis in which acidosis is present. Since the alkali reserve of the blood is depleted in these cases, the natural assumption would follow that the kidney is neither able to excrete the phosphates in the acid form nor after conversion to basic phosphate by the fixed alkali. This brings up the question of whether it is the acid radical or the phosphate group which gives rise to difficulty in excretion. The acidosis of nephritis does not rest even in its ultimate analysis upon a disturbance of the carbohydrate metabolism; it is not accompanied by an increase in the ammonia output in the urine and no abnormal acids have as yet been discovered in the urine. In these details, this acidosis constitutes a very different type from the classical picture of diabetic acidosis, though fundamentally, the underlying principle in the two acidoses are identical. The position of the acidosis occurring in the nephritis of Asiatic cholera is very interesting inasmuch as it is somewhat intermediate between these two types. It conforms to ordinary nephritis in that, except in occasional instances, there is no marked increase in the output of acetone in the urine. Unlike ordinary nephritics and in conformity with diabetic acidosis there is an extremely large output of ammonia in the urine. The ammonia coefficient can be at least partially reduced by the administration of bicarbonate. No especial attention was directed toward the ammonia metabolism in these cases of cholera since, at the time they were studied, the behavior of ammonia in the 
acidosis of ordinary nephritis had not yet been investigated.

Thus from a study of diabetes and nephritis, we are able to pick out the fundamental features which will be found in any acidosis and the incidental features which vary with the type of acidosis, its etiology, and with the more or less accidental circumstances accompanying the condition of the individual patient. Thus in any outspoken acidosis, the tolerance to bicarbonate will be increased, the carbon dioxide content of the blood and alveolar air as well as the titratable alkalinity of the blood will be diminished. In death from acidosis, the actual alkalinity of the blood will decrease slightly, i. e., the hydrogen ion content will rise. In typical chronic diffuse nephritis practically no other features accompany this picture. Of the incidental features, there are only two of primary importance, namely, ammonia and the "acetone bodies." The output of ammonia in the urine, once considered as a cardinal sign of acidosis, may or may not rise, according as to whether the body is able to substitute ammonia for the fixed bases in the neutralization of acids. In diabetes and in Asiatic cholera, the ammonia coefficient usually rises; in ordinary nephritis it remains low. The output of acetone and the "acetone bodies" depends upon whether there is a disturbance of carbohydrate metabolism. They ordinarily increase in diabetic acidosis and occasionally in any acidosis, merely as a starvation phenomenon. It is perhaps worth while to present these features in tabular form. 


\begin{tabular}{|c|c|c|c|c|c|}
\hline \multirow{2}{*}{\multicolumn{2}{|c|}{ Evidences of acidosis }} & \multicolumn{4}{|c|}{ Disease in which acidosis oecurs } \\
\hline & & Diabetes & $\begin{array}{l}\text { Ordinary ne- } \\
\text { phropathies }\end{array}$ & $\begin{array}{l}\text { Nephritis of } \\
\text { Asiatie cholera }\end{array}$ & $\begin{array}{l}\text { "Food intoxi- } \\
\text { cation of } \\
\text { children" }\end{array}$ \\
\hline \multirow{5}{*}{ 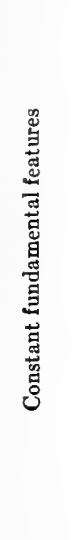 } & $\begin{array}{l}\text { Tolerance to } \\
\text { sodium bicar- } \\
\text { bonate }\end{array}$ & Increased & Increased & Inercased & Incrcased \\
\hline & $\begin{array}{l}\text { Carbon diox- } \\
\text { ide content } \\
\text { of blood and } \\
\text { alveolar air }\end{array}$ & Decreased & Decreased & (Decreased) ${ }^{*}$ & Decreased \\
\hline & $\begin{array}{l}\text { Titratable al- } \\
\text { kalinity of the } \\
\text { blood }\end{array}$ & Decreased & Decreased & (Deereased) $\uparrow$ & Decreased \\
\hline & $\begin{array}{l}\text { Hydrogen ion } \\
\text { concentration } \\
\text { of the blood }\end{array}$ & $\begin{array}{l}\text { Terminal in- } \\
\text { crease }\end{array}$ & $\begin{array}{l}\text { Terminal in- } \\
\text { erease }\end{array}$ & $\begin{array}{l}\text { (Terminal } \dagger \\
\text { increase) }\end{array}$ & $\begin{array}{l}\text { (Terminal } \dagger \\
\text { increase) }\end{array}$ \\
\hline & $\begin{array}{l}\text { Clinical } \\
\text { symptoms }\end{array}$ & $\begin{array}{l}\text { Present in ad- } \\
\text { vaneed stages }\end{array}$ & $\begin{array}{l}\text { Present in ad- } \\
\text { vaneed stages }\end{array}$ & $\begin{array}{l}\text { Present in ad- } \\
\text { vanced stages }\end{array}$ & $\begin{array}{l}\text { Present in ad- } \\
\text { vanced stages }\end{array}$ \\
\hline \multirow{2}{*}{ 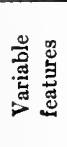 } & $\begin{array}{l}\text { "Acetone } \\
\text { bodies" }\end{array}$ & Increased & Normal & $\begin{array}{l}\text { Usually nor- } \\
\text { mal }\end{array}$ & $\begin{array}{l}\text { Slightly in- } \\
\text { creased }\end{array}$ \\
\hline & $\begin{array}{l}\text { Ammonia } \\
\text { output }\end{array}$ & Increased & Normal & Increased & $\begin{array}{l}\text { Often } \\
\text { increased }\end{array}$ \\
\hline
\end{tabular}

- Not yet demonstrated for the alveolar air.

$\dagger$ These features have not yet been demonstrated experimentally, but theoretically they must occur.

This variation in the excretion of acetone and ammonia in the different types of acidosis is of considerable interest. The behavior of acetone depends directly on the carbohydrate metabolism. The variation of the ammonia is more difficult to understand. In diabetes, large quantities of ammonia are substituted for fixed bases in the neutralization of acids. In the ordinary nephropathies, the body is unable to substitute any ammonia whatever for the fixed bases beyond the

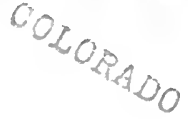


amount, and usually the minimal amount, that is normally neutralized in this way. Perhaps one of the determining factors would be the place of origin of the acid radicals in the body. In the defective oxidation of diabetes, the acid radicals and the ammonia might conceivably be produced in the same tissues of the body or even in the same cells, and neutralization could readily take place. In ordinary nephritis, however, the acid radicals which the kidney fails to excrete might of necessity take up the fixed bases, there being no free ammonia present in the blood stream to effect the neutralization.*

We have, however, to deal not only with the question of why no additional ammonia is used in nephritis; it remains to explain why the amount in diabetes is limited to 40 or 50 per cent of the total that is excreted. The position of the acidosis of cholera is unique. In its etiology, the extensive kidney lesions would apparently justify grouping it with the other nephropathies in which the function of eliminating acid is impaired; the high ammonia coefficient, however, gives it some resemblance to the group typified by defective oxidation of acids as in diabetes.

The observation of the effect of alkali upon a high ammonia coefficient furnishes the all-important distinction between an increase in ammonia due to acidosis and a similar increase due to a primary disturbance of protein metabolism. In an uncomplicated acidosis

* It is not in any sense intended to imply that in nephritis the tissues are unable to produce ammonia but rather that the proper conditions are lacking for its interception by acids. In other words the appropriate stimulus is lacking. Thus in the event of the very unusual development of diabetes with acidosis in a patient with chronic interstitial nephritis one would expect a distinct increase in the urinary ammonia. 
accompanied by a high ammonia coefficient, the administration of bicarbonate, if carried to the point of rendering the urine alkaline, causes the ammonia of the urine to fall promptly to normal or subnormal proportions; the high coefficient represents merely a secondary change in the nitrogenous metabolism for compensatory purposes. In the primary disturbances of the protein metabolism, such as acute yellow atrophy and some of the toxacmias of pregnancy, the percentage of the total nitrogen of the urine which is excreted as ammonia may be both relatively and absolutely increased. Furthermore, this excretion of ammonia is unaffected by the administration of bicarbonate. In advanced diabetes the effect of bicarbonate is sometimes extremely interesting. Unfortunately there are not very many cases of diabetes in which these data are available. In a few which were studied in the early investigation of acidosis, the results proved to be distinctly instructive. In a certain proportion of the cases the ammonia coefficient began to fall upon the administration of bicarbonate. However, with the continuation of intensive alkali therapy the ammonia output failed to continue decreasing but remained persistently high. This result indicates clearly that the high ammonia was due in part to acidosis and in part to a disturbance of protein metabolism, perhaps to an impairment of liver function. Other disturbances of the protein metabolism also occur in diabetes. Occasionally the output of purin nitrogen in the urine is considerably increased. .55

It is generally accepted in man that the increase in ammonia output in acidosis is accompanied by a corresponding decrease in the output of urea, the total nitrogen of the urine remaining constant. An impor- 
tant exception has been discovered by McCollum and Hoagland ${ }^{56}$ who find that for certain omnivora (swine) the increased excretion of ammonia in acidosis represents an increased catabolism of nitrogen and not an interception of ammonia in the formation of urea. There is another difficult feature in the ammonia metabolism which is closely associated with acidosis. In some destructive diseases of the liver parenchyma, the output of ammonia increases markedly, the assumption being that the urea forming function of the liver has been impaired. This view cannot be accepted as altogether satisfactory until some explanation is offered for the failure of the other tissues to take up the function of urea formation. It is noteworthy that in animals with an Eck fistula, the ammonia output increases though apparently no acidosis develops. The entire subject merits reinvestigation in view of the intimate relationship of hepatic lesions to acidosis and to disturbances of the protein metabolism.

One point of very. great importance is the decision as to whether acidosis is the result or the cause of nephritis. From the arguments advanced in this paper, it will be seen that there is strong evidence in favor of the view that the acidosis is a purely secondary phenomenon, as in diabetes, and that it is the result of the nephritis. The development of the symptoms of nephritis may precede, by many months, all of the signs of acidosis; advanced parenchymatous cases occur without signs of acidosis. Certainly, in chronic cases, the relief of acidosis is not followed by the disappearance of nephritis.

In very marked contrast to these views, Martin Fischer ${ }^{35}$ has advanced the idea that acidosis is the cause of nephritis. Fischer considers that there is a 
local production of acid in the kidney substance in contrast to the view that there is a diminished secretion and elimination of acid by the kidney. The decision as to whether acidosis is a primary or secondary factor is obviously of fundamental importance from the standpoint of etiology and therapy. It would be of considerable consequence if we could show that some of the nephropathies are caused by an acidosis and the outlook for treatment would be more hopeful than if we find that acidosis is merely one of several results of nephritis, the cause itself being still obscure in many instances. In the fundamental principle there can be no compromise between these two views. The evidence is overwhelming that the acidosis is not primary but is purely secondary, in nephritis as it is in diabetes, and in all other conditions in which it has been studied.

There is at present no adequate explanation for the acidosis occurring in the so-called "food intoxication" of children. The excretion of "acetone bodies" is not sufficient to indicate any serious disturbance in the processes of oxidation. The signs of renal irritation are not pronounced. There is probably some loss of alkali as such from the bowel but this would not seem to be sufficient to explain these cases. Perhaps a combination of these minor factors might be sufficient to cause a serious depletion of the fixed alkali. It may be that an intensive study will reveal an adequate explanation of these cases.

Regarding the etiology of acidosis, there is one additional possibility which possesses some theoretical interest, namely, the effect of a deficit of fixed bases in the diet, especially during the period of adolescence. The work of Osborne, Mendel and Ferry ${ }^{52}$ has shown the 
importance of a liberal supply of calcium salts for the normal growth of young animals. It might be of some importance to produce an impoverishment of fixed bases in the body by limiting the amount of these in the food supply. Such a chronic acidosis, during the period of growth, might conceivably bear a relation to some of the effects of malnutrition seen in children. 


\section{XI}

\section{RESUME}

Acidosis may be defined as a depletion of the blood and other tissues of the body in fixed bases. There is no accumulation of acid in the blood even in fatal acidoses; in these cases, during the last few days of life, a definite though very slight rise occurs in the hydrogen ion con'centration, but the blood still remains virtually neutral or even faintly alkaline in a physicochemical sense and in its reaction to indicators. The definition should not be limited to the blood nor to the carbonates alone but it should include the other tissues of the body and the other fixed bases and substances which, like the carbonates, can give rise to alkali. Some of the subdivisions of acidosis which have been proposed are essentially misleading. There is no logical foundation for a distinction between relative and absolute types or for a classification of cases into compensated and uncompensated groups.

The distinction between the normal and a state of acidosis is a quantitative one and not qualitative since, even under physiological conditions, the body produces a moderate excess of acid radicals. These are not permitted to appear as such but are immediately disposed of chiefly by oxidation but in part by excretion either with or without neutralization. In acidosis the body protects itself, not by the development of new methods, but by an increased activity of its normal processes, chiefly through increased neutralization by ammonia 
and the fixed bases. This protective mechanism is extremely efficient, maintaining a delicate adjustment of the equilibrium between acids and bases. In the presence of many factors which tend to disturb this equilibrium and even with the extensive formation of acid radicals in the body, the reaction of the blood is maintained with remarkable constancy. The immediate cause of death in acidosis is perhaps not the extremely slight change in reaction per se but rather the lack of normal carbonate for carrying on the function of internal respiration. In contrast to acidosis, there is no adequate evidence for the establishment of the hypothetical condition of alkalosis either in the sense of an increase in the hydroxyl ion concentration of the blood or an increase in the reserve of fixed bases.

Henderson has shown that the precision with which the reaction of the blood is regulated constitutes one of the great constants of the body. In acidosis extensive changes are taking place in the body to maintain this regulation. Since the reaction of the blood remains unaffected other methods must be adopted to detect these changes. The determination of the tolerance to sodium bicarbonate (i. e., the amount of bicarbonate required to render the urine alkaline) has been developed as a test for acidosis. It constitutes the most delicate test which we have, since changes occur in the bicarbonate tolerance before the carbonates of the blood show any definite diminution. Furthermore, it is of general application in all types of acidosis which have been described and it is pathognomonic. By the aid of this test in conjunction with observations on the reaction of the blood to phenolphthalein, it was proven that a moderate degree of acidosis develops comparatively 
early in some of the chronic neplritides. Conclusive proof was also furnished that the high tolerance to bicarbonate found in advaneed nephritis is due essentially to an acidosis. This conclusion was confirmed by demonstrating a marked lowering of the carbon dioxide content of the blood in uraemia. Three cases of diabetes were described in which an acidosis occurred that was not due to the ordinary " acetone bodies."

The establishment of the existence of acidosis in several of the nephropathies broadens our views considerably in regard to the essential features of acidosis. In certain types of uraemia and acute nephritis we have an acidosis fully as severe as any that occurs in diabetes. Yet it is not dependent in any sense upon a disturbance of carbohydrate metabolism, the amount of acetone in the urine remains within normal limits and there is no excretion of the other "acetone bodies." The ammonia excretion both as regards the relative and absolute amounts is not increased. In any acidosis there are several fundamental features which develop as a direct result of the depletion of the body in fixed bases. The tolerance to bicarbonate rises and the carbon dioxide content of the blood and alveolar air as well as the titratable alkalinity of the blood diminishes. In fatal cases there is a slight decrease in the actual alkalinity of the blood just before death. As incidental features in the course of acidosis we may have an increase in the excretion of the "acetone bodies" and of ammonia.

This variation in the ammonia is surprising. It has long been known that the herbivora ean supply ammonia much less readily than the carnivora in the neutralization of acids. ${ }^{57}$ However, it had not been suspected that wide variation occurs in a given species 
according to the mode of origin of the acidosis. The early study of diabetes led to the natural conclusion that in man ammonia was always readily available in acidosis. In the event that nephritis had been studied before diabetes, the reverse impression would have held. In diabetes, although a large proportion ( 50 per cent) of the available ammonia is often utilized, it still remains to explain why all of the ammonia cannot be employed. In nephritis the ammonia excretion often reaches only the lower limits of normal, the more valuable fixed bases being utilized very extensively. It might seem that in the acidoses due to defective oxidation, the ammonia output is high whereas it is normal or even subnormal in those caused by defective renal function. An apparent exception to this proposition is found in the disease, Asiatic cholera, which occupies a unique position; the nephritis is extreme, the acetone output is normal but the ammonia is high. Some information might be obtained in explanation of these difficulties if acidosis could be produced experimentally without increasing the excretion of ammonia.

Three conditions are known in which severe acidosis occurs, namely, diabetes, some of the nephropathies and the so-called "food intoxication" of children. The clinical symptoms of air hunger and coma develop and the acidosis frequently becomes the immediate cause of death. Occasionally pronounced symptoms of acidosis develop in patients with advanced lesions of the liver but these cases have not been adequately studied. Moderate symptoms of acidosis not infrequently develop in acute rheumatic fever and in advanced anaemias. Except for the fact that the compensatory processes operate effectively, it seems not unlikely that the dis- 
turbances arising from acidosis would be much more common. The occurrence of a definite degree of acidosis in uncomplicated cardiac cases has not been established. The tests for acidosis may be very helpful in the rapid differentiation of various comas and in the study of cardiorenal and cerebral lesions.

In the treatment of acidosis with alkalies it should be renembered that the relief of symptoms is due not to the neutralization of acid but to the persistence of the injected carbonates in the body and to their function in carrying carbon dioxide from the tissues to the lungs. Some of the supposedly toxic symptoms of uraemia are due, not to the presence of a toxin, but to the absence of a normal constitutent of the body, namely, the carbonates. The fixed bases especially the carbonates are essential to life. When a depletion of carbonates occurs, the carbon dioxide accumulates in the tissues, the oxygen brought to the tissues by the arterial blood cannot be utilized but is carried away by the venous blood. The effect is equivalent to depriving the individual of oxygen; such patients suffer from symptoms of suffocation and frequently call for " air." From the study of cases of acidosis it is possible to determine in a general way the effect of varying degrees of depletion in the supply of fixed bases in the body. A deficit of 20 or 30 grams can be detected by appropriate laboratory methods but certainly does not produce any clinical symptoms. A deficit of 40 to 50 grams produces changes which can readily be detected by a variety of laboratory methods but still does not spontaneously give rise to clinical symptoms other than dyspnoea on exertion. With an increase of this deficit to 75 or 100 grams dyspnoea may develop and may persist even when patients 
are at rest in bed. More rarely there may also be slight mental confusion. Several patients in whom the deficit amounted to approximately 150 grams of bicarbonate were in partial coma and showed varying but definite evidences of air hunger. The maximum deficits which have been reported either in diabetes or nephritis are about 200 grams. Such patients are always in coma and it would seem that this quantity represents approximately the critical limit of depletion in fixed bases.

The behavior of the fixed bases in acidosis apparently conforms to a somewhat general pathological law that the composition of the blood is maintained in a relatively constant condition at the expense of the other tissues of the body. Thus if the organism suffers a depletion in water or in carbohydrates, the other tissues of the body are drawn upon, even to the point of exhaustion, to maintain a fairly normal composition of the blood in these substances. The physicochemical reaction of the blood is protected and maintained at a constant level with great care.

The requirements are comparatively simple for the appropriate use of alkalies in acidosis. For the fully developed cases in which coma is pending it is necessary to use large injections of bicarbonate intravenously rather than the normal carbonate. Its administration must be controlled in a general way by the examination of the blood serum for titratable alkalinity or carbon dioxide or by the carbon dioxide content of the alveolar air. The exact point at which the administration of alkali should cease must be determined more exactly by carefully following the reaction of the urine. Fortunately the reaction of the urine affords an entirely reliable guide even in patients with advanced lesions of 
the kidney. This fact is of considerable clinical importance. In mild or doubtful cases of acidosis it is entirely permissible to give sodium bicarbonate in 5 gram quantities at two hour intervals until the urine becomes alkaline.

In acute and self-limited conditions accompanied by severe acidosis, treatment with alkalies is sometimes very satisfactory. The best and most uniform results are obtained in Asiatic cholera. In chronic conditions the effect of treatment is so discouraging that the use of alkalies in diabetic acidosis is often neglected and the possibilities of this procedure are by no means fully realized. Some observers even go so far as to advise against the use of alkalies. While the ideal object in diabetes is to prevent the development of acidosis yet when this condition does appear it should be promptly relieved with bicarbonate. This treatment with alkalies is just as essential as the relief of any other form of starvation. In chronic nephritis, acidosis develops comparatively early; it frequently leads to serious discomfort and may prove to be the immediate cause of death. The early relief of this acidosis might possibly have a beneficial effect on the course of the nephritis notwithstanding that a low grade of chronic acidosis is presumably without effect on metabolism. In passing, it might be mentioned that a meat diet, so often detrimental to nephritics, is comparatively rich in the acid end-products of catabolism.

In chronic acidosis it is therefore a long and difficult problem to determine the clinical effect of treatment; on the other hand the changes produced in the laboratory findings by the injection of alkali are prompt and easily recognized. The carbon dioxide content of the 
alveolar air and the blood rises rapidly to normal. The titratable alkalinity of the blood increases and the tolerance to bicarbonate of course decreases. In diabetes the ammonia output falls but it is extremely important to determine whether the ammonia excretion can be reduced to normal. A polyuria often ensues accompanied by an increased excretion of the "acetone bodies " owing to a flushing out of the tissues.

The etiology of the known acidoses resolves itself into two fundamental types namely, defective oxidation of organic acids as typified by diabetes and defective elimination more especially of the mineral acids as found in the ordinary nephropathies. There are certain things which suggest that perhaps the nephritis of cholera represents a combination of these two types.

One of the essential functions of the kidney is the rather remarkable separation of a sharply acid urine from a slightly alkaline blood plasma. Impairment of this function is apparently one of the principal factors in the development of acidosis in nephritis. Notwithstanding the progressive development of the renal lesions, the kidney retains, in a very considerable degree, its remarkable ability of separating and excreting acids and acid salts from a slightly alkaline plasma. This is one of the last functions of the kidney to be lost, persisting as long as fluid is excreted.

No adequate explanation has as yet been offered for the extreme acidosis occurring in children.

Before dismissing the subject of acidosis, it might be well to mention again the points arising in this discussion on which the information at present is incomplete. The extent to which acidosis occurs in diseases involving the liver cannot be determined until laboratory data are 
available. There is urgent need for some alleviating measures in chronic nephritis and the early treatment of acidosis is a logical procedure and offers possible, even though minor assistance. Another feature of treatment which merits attention is the replacement of calcium and magnesium as well as the carbonates. The explanation of the ammonia metabolism in nephritis is an involved and interesting problem. Its behavior cannot be completely understood until further investigations are made in Asiatic cholera. It is not inconceivable that an acidosis of a special type might result from the withholding of the normal fixed bases of the food. During the adolescent period such a deprivation might result in the production of unusual features which would not be possible in adult life. 

XII

APPENDIX 



\section{APPENDIX}

\section{TECHNIQUE OF METHODS}

In the following pages only those methods will be described which have been developed recently and which are of clinical importance. The older methods for the study of diabetic acidosis are well known. The determination of the ammonia coefficient is now extremely simple. No fundamental changes have been introduced in Kheldahl's method for total nitrogen but the introduction of micro-methods by Folin has reduced the required laboratory facilities to a minimum. The determination of ammonia was formerly greatly hindered by the ease with which the urea of the urine changed to ammonia under the influence of heat and alkalies. This difficulty has been entirely obviated by Folin's methods of removing the ammonia from the urine by aëration in the cold. The removal is quantitative and the ammonia is absorbed in standard acid and measured by titration. ${ }^{58}$ The acetone and $\beta$-oxybutyric acid content of the urine can be very readily determined by Shaffer's method. ${ }^{59}$ The acetone is first distilled off, the remaining $\beta$-oxybutyric acid being oxidized with potassium bichromate to acetone and carbon dioxide. The quantity of acetone is determined volumetrically with standard iodine. Marriott has also developed a method for the determination of acetone and $\beta$-oxybutyric acid in the blood and tissues. ${ }^{60}$

Those methods which serve for the detection of any acidosis regardless of its mode of origin are of especial interest. Some of these will be described in detail.

Carbon Dioxide Content of the Alveolar Air. This determination resolves itself into two phases, namely, (1) the collection of the specimen, and (2) its analysis. There is a choice 
of two types of methods for the collection of samples of alveolar air. In one type, after a normal expiration, the residue of alveolar air is expelled by a forcible deep expiration and caught in a suitable tube; in the other, the subject is required to rebreathe a small volume of air in an ordinary rubber bag for half a minute. Haldane devised the method for collecting the alveolar air by a forcible expiration. There are several modifications of this type all of which require more or less skill on the part of the subject. Boothby and Peabody ${ }^{61}$ have improved the method by the introduction of certain automatic features in the apparatus for collecting and traping the expired air; even with this advancement these authors do not recommend this type of method except for special investigations on trained subjects or for patients who can coöperate readily. Under such conditions the Fridericia ${ }^{62}$ method is perhaps the simplest and it is sufficiently accurate for clinical purposes. The alveolar air is caught by forcible expiration in a glass tube, the carbon dioxide is absorbed by caustic soda and the decrease in volume is measured on a scale reading in percentages by volume. A very careful and accessible description of the method is given by Poulton ${ }^{62 a}$ in which the main features are as follows. A convenient form of the apparatus is illustrated in Figure 1. $\mathrm{M}$ is a mouthpiece. A is an ordinary two-way and B a three-way stopcock of rather wide bore (10 millimeters). Three positions of the stopcock $B$ are required during the procedure in the following order, namely:

Position I. In which $\mathrm{X}$ and $\mathrm{Y}$ communicate, the outlet $\mathbf{C}$ being cut off.

“ II. $\mathrm{Y}$ and $\mathrm{C}$ communicate, $\mathrm{X}$ being cut off.

" III. $\mathrm{X}$ and $\mathrm{C}$ communicate, $\mathrm{Y}$ being cut off.

The total volume of $\mathrm{X}$ between $\mathrm{A}$ and $\mathrm{B}$ must be exactly 100 c.c. and the scale in the narrow stem of $X$ is graduated in cubic centimeters or, to obviate the difficulty of constructing $\mathrm{X}$ to contain exactly 100 c.c., an approximate size may be 


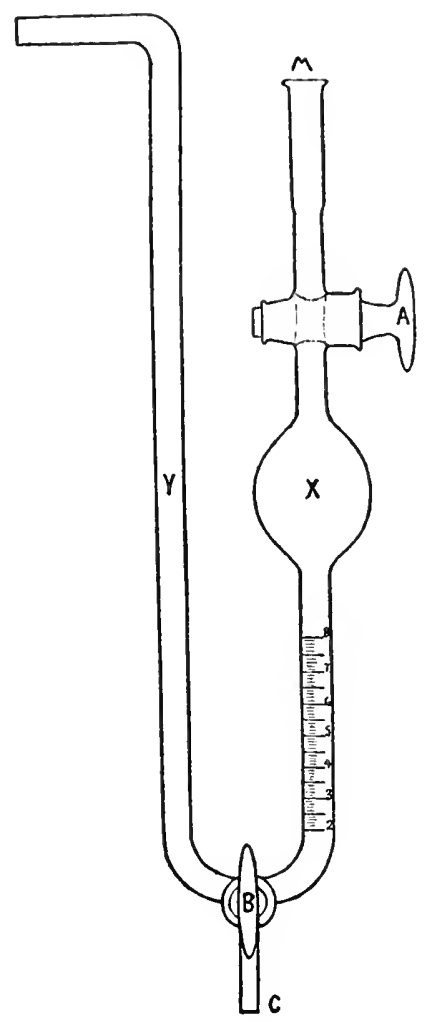

Fig. 1. Fridericia Apparatus. 

used; the volume is then determined exactly and the scale is graduated in percentages of this volume up to eight per cent. The subject must breathe quietly into the apparatus with the tap $\Lambda$ open and $B$ in Postition I. At the end of a normal inspiration he blows hard and quickly through the apparatus and the operator closes tap A leaving B unchanged. Inasmuch as the total volume of the forced expiration is about two liters this procedure displaces all the air in the apparatus and leaves it filled with alveolar air. The apparatus is placed in a water-bath at room temperature. On cooling, alveolar air in the bottom of $\mathrm{Y}$ is drawn into $\mathrm{X}$ but there is no danger that the atmospheric air drawn into the top of $\mathrm{Y}$ can reach $\mathbf{X}$. After five minutes the stopcock $\mathrm{B}$ is turned into position II connecting $\mathrm{Y}$ and the outlet, but closing $\mathrm{X}$. By means of suction at the top of $\mathrm{Y}$ (a rubber bulb) 20 per cent sodium hydroxide (about 2 or 3 c.c.) is sucked into $\mathrm{Y}$. With $\mathrm{X}$ and $\mathrm{Y}$ in communication (Position I) the soda is forced under slight pressure into $\mathrm{X}$ compressing the alveolar air to admit the addition of the soda keeping the stopcock A closed. During the manipulation the arm $\mathrm{Y}$ is depressed slightly and $\mathrm{X}$ is elevated to prevent any alveolar air escaping through $\mathrm{B}$. The next step consists in closing $\mathrm{X}$, turning the stopcock to Position II and the caustic soda remaining in $\mathrm{Y}$ is allowed to run out. The apparatus is inverted with gentle shaking for a half minute to effect the absorption of the carbon dioxide; it is then returned to the water-bath, and the stopcock $\mathrm{B}$ turned with the tap $\mathrm{C}$ under water so that $\mathrm{X}$ communicates through $\mathrm{C}$ with the water (Position III). After five minutes the instrument is raised till the water stands at the same level in $\mathrm{X}$ and in the water-bath. This operation brings the gas in $\mathrm{X}$ to the same conditions of temperature and pressure as before absorption. Consequently the reading at the meniscus of the fluid in the stem of $\mathrm{X}$ represents without any correction the percentage of carbon dioxide in the sample since no allowance is made for the water vapor taken up by the alkali; this correction for the absorbed water 
vapor would fall within the limits of error of the method. If it is desired to transpose these figures to millimeters of mercury for the corresponding conditions of temperature pressure and water vapor one need only multiply the barometer reading by the percentage. Thus at sea level a normal reading of 5.5 per cent would correspond to about 42 millimeters of mercury. In cleansing the apparatus, it is well to use a little dilute acid to insure freedom from any trace of alkali.

In the process of collecting the sample there are two precautions which the patient must be taught to observe. In the first place there is an involuntary tendency to take a deep inspiration before the forced expiration. This dilutes the sample and gives readings that are too low, sometimes by one-half per cent. If this error of deep breathing is overcorrected and the breath is held even for a few moments ( 5 seconds) before the expiration, then the results will be too high (one-half to one per cent).

While the Fridericia method is very simple and sufficiently accurate for trained subjects it is unsuitable for a comparatively large group of subjects such as patients in more or less complete coma and in the case of infants. For routine clinical purposes, Plesch's procedure of rebreathing air has become generally adopted. The most satisfactory form of this method is the Plesch-Higgins modification. The exact details as employed by Boothby and Peabody ${ }^{61}$ are as follows: A soft rubber bag of one and one-half to two liters capacity is provided with a mouthpiece. Between the mouthpiece and the bag it is desirable to introduce a three-way stopcock so that the subject can breathe through the mouthpiece either to the outer air or into the bag. This stopcock should have a large lumen (one-half inch) to permit free and natural breathing. A small tube with an ordinary stopcock should also be added to the apparatus for the purpose of withdrawing samples of air for analysis. In trained individuals who can coöperate freely it is possible to dispense with the three-way 
stopcock. Even in comatose patients and in children some workers use a simple bag without the stopcock, but this routine tends to diminish one's confidence in the samples which are obtained. By displacement with water the bag is partially filled with air using approximately 1000 cubic centimeters. Except for purposes of special study it is sufficient to introduce very roughly about this amount with a rubber bulb. Next the three-way stopcock is opened to the outer air and the subject with the nostrils compressed breathes quietly through the mouthpiece for several respirations. Then at the end of a normal expiration the stopcock is turned and the subject breathes into the bag for 20 to 30 seconds only, preferably for 25 seconds taking 5 moderately decp breaths. If the depth and rate of breathing cannot be controlled, a correction may be made by slightly altering the time period and the final result is not greatly affected. Modifications of this technique are often necessary for patients in more or less complete coma and for children. For such cases the mouthpiece must be supplemented by a mask made of a thin sheet of rubber. Suitable technique for infants has been worked out by Howland and Marriott. ${ }^{63}$ A smaller bag, one of 500 c.c. capacity, is partially filled with air from an aspirator bulb using 250 c.c. to 400 c.c. according to the age of the subject. The initial amount should be such that at the end of inspiration, the bag is from one-half to two-thirds empty. The child is allowed to breathe into the bag for one-half minute. Vigorous crying just before collection lowers the tension while crying during the collection is an advantage and raises the tension only an insignificant amount.

After the collection of the sample the estimation of the carbon dioxide may be made by any of the standard methods for gas analysis. The Haldane method of gas analysis is very satisfactory for those who wish to go into the subject rather thoroughly. ${ }^{64}$ For clinical purposes the Fridericia method is sufficient. The specimen of gas should be thoroughly mixed in the rubber bag and then transferred to the sample bulb 
(X in Fig. 1) of the Fridericia apparatus. This may be readily done by washing out the atmospheric air with a few hundred cubic centimeters of the sample of alveolar air. If preferred the bulb may be filled by displacement of water or mercury. The absorption of the carbon dioxide with soda is then carried out as previously described.

Marriott ${ }^{17}$ has recently introduced a simple method of analysis in which a solution of alkali is saturated with the mixture of gases to be analyzed. The reaction of the alkaline solution changes in proportion to the amount of carbon dioxide contained in the alveolar air, the greater the amount of carbon dioxide (carbonic acid), the less alkaline the solution becomes. Solutions of sodium hydroxide or sodium bicarbonate will readily take up carbon dioxide according to the following equations:

$$
\begin{aligned}
& 2 \mathrm{NaOH}+\mathrm{CO}_{2}=\mathrm{Na}_{2} \mathrm{CO}_{3}+\mathrm{H}_{2} \mathrm{O} \\
& \text { and } \\
& \mathrm{Na}_{2} \mathrm{CO}_{3}+\mathrm{CO}_{2}+\mathrm{H}_{2} \mathrm{O}=2 \mathrm{NaHCO}_{3}
\end{aligned}
$$

The striking feature of these reactions is that they do not go to completion. A high concentration of carbon dioxide will result in the formation of large quantities of bicarbonate and smaller proportions of carbon dioxide in proportionately smaller amounts. This difference cannot be overcome by employing larger amounts of the weaker mixture of carbon dioxide and prolonging the length of time which it is bubbled through the alkali. The alkaline solution soon comes into equilibrium with a given mixture of carbon dioxide and air and is then unable to absorb any additional carbon dioxide from this mixture; the carbon dioxide escapes from solution notwithstanding that there is considerable sodium hydroxide and sodium carbonate which is not converted to bicarbonate. If to such a solution one adds some sodium bicarbonate it could not remain as such but would be in part converted to the carbonate and hydroxide. The change involved in maintaining this equilibrium after the addition of the bicarbonate 
may, under appropriate conditions of concentration, be represented by the following reaction,

$$
2 \mathrm{NaHCO}_{3}=\mathrm{Na}_{2} \mathrm{CO}_{3}+\mathrm{I}_{2} \mathrm{O}+\mathrm{CO}_{2},
$$

the carbon dioxide escaping from the solution. It is indeed surprising to see the solution become more alkaline as the carbon dioxide is passed through it.

The application of these principles is very simple. The sample of alveolar air is bubbled through a few cubic centimeters of a standard alkali (carbonate, bicarbonate or liydroxide) and the resulting reaction is proportional to the tension of carbon dioxide in the specimen of alveolar air. The reaction may be conveniently determined colorimetrically with phenolsulphonephthalein as indicator. This reagent varies in color according to the degree of alkalinity of the solution; the more strongly alkaline solutions being red, the faintly alkaline ones orange and slightly acid solutions are yellow. A scale of color standards is prepared from 1/15 molecular stock solutions of acid potassium phosphate $\left(\mathrm{KH}_{2} \mathrm{PO}_{4}\right)$ and the dibasic sodium phosphate $\left(\mathrm{Na}_{2} \mathrm{HPO}_{4}\right)$. Of the recrystallized acid potassium phosphate 9.078 grams are dissolved in distilled water, 200 c.c. of 0.01 per cent phenolsulphonephthalein are added and the total volume made to one liter. For the alkaline sodium phosphate the recrystallized salt $\left(\mathrm{Na}_{2} \mathrm{HPO}_{4} .12 \mathrm{H}_{2} \mathrm{O}\right)$ is exposed to the air for two weeks thereby losing 10 molecules of water of crystallization. Of the salt containing two molecules of water, 11.876 grams are dissolved in water, 200 c.c. of 0.01 per cent phenolsulphonephthalein are added and the total volume made up to one liter as for the acid salt. The following table gives the gradations of color standards recommended by Marriott and the corresponding equivalent of carbon dioxide in terms of its tension in millimeters of mercury. 


\begin{tabular}{l|c|c|c|c|c|c|c|c}
\hline \hline & \multicolumn{7}{|c}{ Serial number } \\
\cline { 2 - 6 } & 1 & $z$ & 3 & 4 & 5 & 6 & 7 & 8 \\
\hline $\begin{array}{l}\text { Acid potassium phos- } \\
\text { phate c.c. ......... }\end{array}$ & 17.8 & 25.2 & 31.0 & 35.7 & 40.5 & 45.0 & 47.0 & 50.2 \\
\hline $\begin{array}{l}\text { Alkaline sodium phos- } \\
\text { phate c.c. ......... }\end{array}$ & 82.2 & 74.8 & 69.0 & 64.3 & 59.5 & 55.0 & 53.0 & 49.8 \\
\hline $\begin{array}{l}\text { Tension of CO } \\
\text { mercury) corresponding } \\
\text { to this reaction }\end{array}$ & 10 & 15 & 20 & 25 & 30 & 35 & 40 & 45 \\
\hline \hline
\end{tabular}

These standards must be kept in closed tubes and protected from the light. The standard alkali $\frac{(\mathrm{N})}{(100)}$ is made by dissolving 0.53 gram of anhydrous sodium carbonate in water, adding the usual 200 c.c. of 0.01 per cent phenolsulphonephthalein and making the total volume up to one liter. It is desirable to pass the breath from the lungs through this to the point of saturation in order that the carbonate content shall correspond approximately to that of normal alveolar air; then if it is too high or too low, it will adjust itself to the reaction corresponding to the alveolar specimen with which it is aërated. For the analysis, a few cubic centimeters of the standard alkali are poured into a tube of the same dimensions as those containing the color standards. The operator adjusts this approximately with his own breath. Then about 100 c.c. of the alveolar air under examination are blown rather rapidly (in 30 seconds) through the solution from a capillary pipette. When no further change in color occurs, it follows that the solution is saturated; its color is then compared with the standards. Marriott recommends that this should be done against a ground glass background using an apparatus of the type of the Sahli-haemoglobinometer but 
holding not less than 3 tubes. After the comparison has been made the same solution may be used repeatedly for new determinations.

Experience in various laboratories has shown that this method is satisfactory for elinical purposes in the hands of careful workers provided one is occasionally in a position to check the results with more elaborate equipment. It is highly desirable that a person enploying this method should control his technique from time to time by some of the other methods for carbon dioxide analysis.

\section{Examination of the Blood}

In the examination of the blood the principal features concerning acidosis are the titratable alkalinity, the carbon dioxide content and the physicochemical reaction.

Reaction of Serum to Phenolphthalein after Removal of the Proteins. Numerous methods have been devised for measuring the titratable alkalinity of the blood against dilute standard acid using preferably methyl orange as indicator. The end point is extremely vague and the differences between the normal and pathological are at best only suggestive and not definite. One serious interfering factor is the protein of the serum.

To obviate some of these difficulties the following departure was made from the usual titration methods, ${ }^{25}$ (1) an indicator was selected to which unheated blood serum ordinarily reacts acid, in contrast to litmus or the diazo group to which serum reacts distinctly alkaline, (2) the interfering protein was removed, and (3) a solvent was ehosen which would decrease the ionization of the carbonates so that they would give rise to less alkali than when dissolved in water. These changes are made with the objeet of reducing the normal titratable alkalinity to a minimum. In acidosis this alkalinity disappears altogether and one has at once a definite qualitative test for its deteetion. The removal of protein and the substitution of another solvent for water was ac- 
complished in one step by precipitation with alcohol. The behavior of indicators in alcoholic solution is very interesting. If a little alkaline phenolphthalein dissolved in water and alcohol is poured into a beaker of pure alcohol, the color is at once discharged. This is due not to any traces of acid in the alcohol but to a decrease in the ionization of the hydroxide in alcohol. Consequently, in order to produce a red color with phenolphthalein, a larger amount of alkali must be used in alcoholic than in aqueous solution.

In the selection of an absolute ethyl alcohol for alkalinity work, it must be noted that different specimens vary considerably. Many contain appreciable amounts of alkali on account of the use of metallic sodium for removing the last traces of water. Occasionally definite traces of acid are present, some of the volatile acids formed during fermentation having distilled over with the alcohol. The following procedures are sufficient to determine the suitability of a sample of alcohol. To test for alkalies, 50 c.c. are mixed with a drop of phenolphthalein and evaporated to dryness on a waterbath. The residue should be colorless and should remain colorless on taking up in a drop of water. To test for acid, 50 c.c. are mixed with 0.1 c.c. of $\mathrm{N} / 100$ sodium hydroxide and evaporated to dryness with phenolphthalein. The residue, if not red on going to dryness, should become red on adding a drop of water. These tests are moderately severe and many grades of absolute alcohol fail to conform to them. The reaction is much more important than the percentage of water. It is usually comparatively easy to obtain $\mathbf{9 5}$ per cent alcohol free from any alkali. Preliminary tests indicate that the presence of this 5 per cent of water is not disadvantageous.

This test as employed in the work on nephritis was as follows: one c.c. of serum was added drop by drop to 25 c.c. of alcohol contained in a test tube and the mixture was thoroughly shaken. The precipitated proteins were filtered off using perfectly dry apparatus so as to exclude all water except that which was contained in the serum. Without washing 
the precipitate, the filtrate with a few drops of phenolphthalein was evaporated to dryness on a water-bath. With all normal sera, the alcoholic filtrate soon turns red and on going to dryness the residue, if kept hot, retains its red color for several hours (at least six to eight). With an early acidosis (a deficit of 20 to 30 grams of bicarbonate) the alcoholic filtrate must become rather concentrated before the red color appears and on going to dryness the red color may disappear within a few minutes. Specimens were usually observed frequently for fifteen minutes. Such residues, even though the color may be very faint on going to dryness, become distinetly red on adding a drop of water. It should be noted that just before going to dryness the solution contains its highest proportion of water. With more advanced depletion of bicarbonates (such as 75 or 100 grams), no red color appears at any stage of the evaporation but the residue becomes pink or red on adding water. With well marked acidosis (150 grams deficit of bicarbonate) the residue remains colorless even on taking up in water. In very extreme cases the whole serum when diluted with water (9 parts) and boiled fails to react alkaline with phenolphthalein.

Titration of the residue with dilute sodium hydroxide (N/200), after the evaporation of the alcohol, was carricd out in some instances but the results were not of especial importance.

The principle of titration by electrometrie methods is extremely simple. The point of neutralization of an acid by an alkali is readily determined by conductivity measurements. On mixing an acid and an alkali the conductivity decreases as the neutral point is approached reaching its minimum exactly at neutrality. Then the addition of either acid or base, but especially of acid, causes the conductivity to increase since the hydrogen and hydroxyl ions are better conductors than the neutral ions.

The details of this method are fully deseribed in the literature. ${ }^{27-66}$. They will not be repeated here primarily because 
this determination is not of clinical interest in the study of acidosis. Henderson and many other workers have emphasized that the hydrogen ion concentration of the blood does not change except as a terminal event. While it was of the utmost importance to establish this fact, further confirmation of its seems superfluous.

Considerable importance has recently been attached by Rowntree to a colorimetric test for studying the reaction of the blood. Rowntree and his associates ${ }^{14-67}$ separated the protein of the blood by dialysis testing the dialysate with phenosulphonephthalein, either with or without the addition of dilute (N/50) acids and alkalies. The dialysis of blood and blood serum obviously introduces many factors which would alter the hydrogen ion concerntration. Rowntree ${ }^{14}$ considers that by a happy counterbalancing of errors the net result approximates closely the original hydrogen ion concentration of the blood. Unfortunately the hydrogen ion concentrations which are obtained do not support the view of Henderson just mentioned. Occasionally marked change is found in conditions in which the evidence of acidosis is not definite. Moreover in acidosis, extreme values are found such as have not been discovered by precise electrometric measurements. The authors also report that normal values may occur in definite acidosis. The method therefore loses considerably in clinical interest since several reliable methods are available for the accurate diagnosis of acidosis.

The reaction of the dialysate of the serum is of interest in its bearing on the question of what fractions of the alkaline factors in the serum are dialysable. In some early work Brandenburg ${ }^{68}$ maintained that the alkaline content of the serum was divisible into two fractions, namely, (1) the diffusible mineral alkali, largely the carbonates, a fraction that is small in amount and relatively constant, (2) and a second fraction of alkali that is bound to the protein and is not diffusible, this being the fraction which is responsible for the variation in sera. In the work with the reaction to the 


\section{APPENDIX. TECHNIQUE OF METIODS 107}

protein-free filtrates to phenolphthalein, ${ }^{25}$ the view was expressed that contrary to Brandenburg's position, the carbonates constituted an important factor in the alkali reserve of the blood and that they were subject to variation. 'The work of Rowntree on the variation in the reaction of the protein-free dialysate to phenolphthalein also fails to support Brandenburg's conchusion.

For routine clinical purposes the deternination of the carbon dioxide content of the alveolar air does not require to be supplemented by the same determination upon the blood. Under special conditions and for special purposes, the determination of the carbon dioxide content of the blood may he very valuable. In seeking confirmation of the evidence of acidosis in nephritis I have described an adaptation of Warburg's method for determining relatively small quantities of carbon dioxide and permitting the use of moderately large amounts of blood. ${ }^{24}$ This method however was intended only for special investigations of unknown conditions and was not adapted for routine work. A method for clinical purposes has recently been devised by Van Slyke ${ }^{65}$ permitting rapid and accurate determinations on small quantities of blood.

\section{Determination of the Tolerance to Sodium Bicarbonate}

This test may be carried out either by the ingestion or intravenous injection of bicarbonate. For the detection of a slight increase in tolerance it is quite sufficient to give 5 grams of sodium bicarbonate by mouth every 2 or 3 hours until the urine becomes neutral or alkaline to litmus. The bicarbonate should be given in a moderate amount of water and the patient should void before each administration. Specimens of urine which are not distinctly acid should be boiled thoroughly to convert bicarbonate to carbonate so that it will react readily to litmus. As a control for the 
tolerance tests, Palmer and Henderson have recommended the colorimetric determination of the hydrogen ion concentration of the urine rather than the reaction to litmus. However, the same conclusions regarding the dosage which is required to change the reaction of the urine can be obtained much more simply by the use of litmus paper.

Intravenous injection may be required if abnormalities of the gastrointestinal tract exist and when large doses of bicarbonate become necessary. Even in a normal person without any acidosis as much as 3 to 5 grams of bicarbonate can be given intravenously without discomfort and of course can be repeated at intervals of 2 or 3 hours until the reaction of the urine changes. In outspoken acidosis massive injections of bicarbonate are indicated. A very ordinary dose for intravenous injection would be one-half liter of a 4 or 5 per cent solution repeating this dosage every 4 to 6 hours. A liter of 5 or 6 per cent solution given slowly over a period of one-half to one hour should be regarded as a maximal dose. One must approach with some caution the point at which the urine is about to change over to an alkaline reaction. Examination of the urine gives no warning of this approaching change. Observations on the reaction of the blood serum to phenolphthalein or determinations of the carbon dioxide of the blood or alveolar air will give suitable evidence. As these factors become nearly normal, the dosage of bicarbonate should be reduced at least to about ten grams. There is often some hesitation about giving large volumes of fluid intravenously on account of the possibility of dilatation of the right side of the heart. However, even with cardiac lesions, provided they are compensated, an injection of one-half liter of solution can safely be given intravenously provided it is injected very slowly (three quarters to one hour) by the gravity method. These figures apply only to the "bicarbonate" and not to the normal carbonate. Moreover, precautions must be used in sterilization to prevent excessive 
formation of the carbonate. Even at room tempcrature the bicarbonate is hydrolyzed according to the equation

$$
2 \mathrm{Na}^{\prime} \mathrm{ICO}_{3}^{\prime} \rightleftharpoons \mathrm{Na} \cdot \mathrm{NaCO}_{3}^{\prime}+\mathrm{H}^{\cdot} \mathrm{OH}^{\prime}+\mathrm{CO}_{2},
$$

the carbon dioxide escaping from solution and the normal carbonate and water immediately hydrolyzing as follows:

$$
\mathrm{Na}^{\cdot} \mathrm{NaCO}^{\prime}{ }_{3}+\mathrm{H}^{\cdot} \mathrm{OH}^{\prime} \rightleftharpoons \mathrm{Na}^{\cdot} \mathrm{OH}^{\prime}+\mathrm{Na}^{\cdot} \mathrm{HCO}^{\prime}{ }_{3} .
$$

These reactions being reversible, the exact equilibrium that is established varies with the proportion of these salts, the dilution and the temperature. On boiling such a solution the carbon dioxide is driven off very rapidly with conversion of the bicarbonate to normal carbonate. On sterilization in the autoclave, less change takes place since the carbon dioxide cannot excape from the closed vessel; it eventually comes into equilibrium with the solution and prevents further change. With a little precaution a sterile solution of a five per cent bicarbonate can be obtained containing an amount of normal carbonate so small that at least it is not disadvantageous. Strong narrow-mouthed bottles are filled almost full of bicarbonate solution so as to reduce the air space to a minimum. Tightly fitting stoppers should be tied in place. If there is not much leakage, this in itself will secure a suitable solution composed largely of bicarbonate. However, as an additional precaution, these bottles can readily be sterilized in an atmosphere of carbon dioxide. To secure this, the autoclave is raised to the boiling temperature and water at the boiling point is provided (either in the bottom of the autoclave or in an open dish). The sealed bottles of bicarbonate solution are put in the heated autoclave and a handful of bicarbonate is thrown into the hot water. The door of the autoclave is closed at once and the carbon dioxide allowed to evolve for a moment displacing the air of the autoclave, preferably through a vent at the top. Then the autoclave, is sealed and no steam should be allowed to escape at any time 
in the sterilization. The autoclave must be cooled to room temperature to permit reabsorption of carbon dioxide in case sealing of the bottles was imperfect. Such solutions, if well stoppered, will keep for months. Some silica may gradually scale off but the sterile clear solution can usually be decanted from this.

Sterile bicarbonate may also be obtained in an entirely different manner. The normal carbonate or bicarbonate after sterilization by heat can be converted to bicarbonate by passing a stream of carbon dioxide through the solution after cooling to room temperature.

It is only on rare occasions that any complication comes up with regard to the reaction of the urine to litmus. Some special consideration should be given to those cases where there is ammoniacal fermentation in the genito-urinary tract. Even in these patients the bicarbonate tolerance can be readily determined since the distinction between ammonia and the fixed bases is readily made. The simple device of merely heating the litmus paper is often sufficient. Red litmus paper which has been turned blue by ammoniacal urine will regin its red color on drying and heating provided that the specimen of urine was originally acid before fermentation; otherwise it will remain blue on heating. This test, while it was found adequate in many instances, sometimes gave indecisive results, the litmus occasionally becoming more or less discolored in heating. For these cases, the urine was heated to boiling over a free flame, maintaining an adequate volume of fluid by the addition of water, until no trace of ammonia was given off. The urine then possesses the reaction which it had before fermentation. This procedure may be tested very easily by taking a specimen of normal acid urine, making it alkaline with ammonia and then boiling. The acid reaction will return comparatively soon. If fixed base is added, such as sodium hydroxide, the acid reaction cannot return and moreover ammonia will be given off from the breaking up of the urea. Moreover, if much hydroxide is 


\section{APPENDIX. TECHNIQUE OF METHODS 111}

added, the driving off of all the ammonia may become a considerable undertaking neessitating the breaking up of all of the urea.

If it is desired to make elaborate investigations of the acidity of the urine, comparatively simple methods are available for determining either the titration values ${ }^{69}$ or the hydrogen ion content colorimetrically. ${ }^{23}$ Numerous studies of this nature have not yet revealed any conditions in which these data are of especial elinieal interest. 


\section{BIBLIOGRAPHY}

1. Boussingault, M. Recherches sur la Quantité d'Ammoniaque Contenue dans l'Urine. An. de Chimie et Physique, 1850, 3me, 29, 472. Translated in Jour. für Praktische Chemie, $1850,51,281$.

2. Foun, O. The Acid Intoxication Theory. Tr. Assn. Am. Phys., 1907, 22, 256.

3. Hallervorden, E. Ueber Ausscheidung von Ammoniak in Urin bei pathologischen Zuständen. Arch. f. exper. Path. u. Pharmakol., 1879-80, 12, 237.

4. Stadelanann, E. Ueber die Ursachen der Pathologischen Ammoniakausscheidung beim Diabetes mellitus und des Coma diabeticum. Arch. f. exper. Path. u. Pharmakol., 1883, 17, 419.

5. Walter F. Untersuchungen über die Wirkung der Säuren auf den Thierischen Organismus. Arch. f. exper. Path. u. Pharmakol., 1877, 7, 148.

6. Kussmaul, A. Zur Lehre vom Diabetes mellitus. Deutsch. Arch. f. klin. Med., 1874, 14, 1.

7. Henderson, L. J. The Regulation of Neutrality in the Animal Body. Science, 1913 (New Series), 37, 389. Ibid., Ergebnisse der Physiol., 1909, 8, 254.

8. Jones, H. C. Elements of Physical Chemistry. 1910, 4th ed., page 439.

9. Henderson, L. J. The Theory of Neutrality Regulation in the Animal Organism. Am. Jour. Physiol., 1908, 21, 427.

10. JANNEY, N. Die Ammoniakausscheidung im menschliche Harne bei Zufuhr von Harnstoff und Natron. Ztschr. f. physiol. Chem., 1911-12, 76, 99.

11. Wilson, D. W., Stearns, T., Janney, J. H., Jr. The Effect of Acid Administration on Parathyroid Tetany. Jour. Biol. Chem., 1915, 21, 169.

Wilson, D. W., Stearns, T., Thurlow, M. DeG. The AcidBase Equilibria in the Blood After Parathyroidectomy. Jour. Biol. Chem., 1915, 23, 89.

Wilson, D. W., Stearns, T., Janney, J. H., Jr., The Excretion of Acids and Ammonia after Parathyroidectomy. Ibid., 1915, 23, 123. 
12. Benedict, II. Der IIydroxylionengehalt des Diabetikerblutes. Arch. f. d. gesam. Physiol., 1906, 115, 106.

13. Hasselibalcu, K. $\Lambda$. and Gamaeltoft, S. $\Lambda$. Die Neutralitiatsregulation des graviden Organismus. Biochem. Ztschr., $1915,68,233$.

14. Rowntree, L. G. The Diagmosis and Treatment of Acidosis. Tr. Assn. Am. Phys., 1916, 31, 39.

15. Walker, I. C. and Frotminglinu, C. A Comparison, in Various Diseases, of the Carbon dioxide Tension in the Alvcolar Air (I'lesch Method) with the Amount of Carbon dioxide in the Venous Blood (Van Slyke's Method). Arch. Int. Med., $1916,18,304$.

16. Van Slyke, D. D., Cullen, G. E., Stillanan, E. Changes in Blood Alkalinity during Digestion. Proc. Soc. Exper. Biol. and Med., 1915, 12, 181 .

17. Marriott, W. McK. The Determination of Alveolar Carbon dioxide Tension by a Simple Method. Jour. Am. Med. Assn., 1916, 66, 1594 .

18. Porges, O., Leindörfer, A., Markovici, E. Ueber die Kolılensäurespanmung des Blutes in pathologischen Zuständen. Ztschr. f. klin. Med., 1911, 73, 389.

19. Douglas, C. G., Haldane, J. S., Henderson, Y., Schneider, E. C. The Physiological Efiects of Low Atmospheric Pressures as Observed on Pike's Peak, Colorado. (Preliminary Communication.) Proc. Roy. Soc. of London, Series B, $1912,85,65$.

Douglas, C. G., Haldane, J. S., Henderson, Y., SchneiDER, E. C. Physiological Observations made on Pike's Peak, Colorado. Philosophical Transactions of the Royal Society of London, Series B, 1912-13, 203, 185.

Haldane, J. S. Organism and Environment as Illustrated by the Physiology of Breathing. 1917.

20. Cammidge, P. J. Diabetic Acidosis. Am. Med., 1916, 22, 363.

21. Sellards, A. W. Tolerance for Alkalies in Asiatic Cholera. Philippine Jour. Sc., Sec. B, 1910, 5, 363.

22. Sellards, A. W. The Determination of the Equilibrium in the Human Body Between Acids and Bases with Especial Reference to Acidosis and Nephropathies. Bull. Johns Hopkins Hosp., 1912, 23, 289.

23. Palmer, W. W. and Henderson, L. J. Clinical Studies on Acid Base Equilibrium and the Nature of Acidosis. Arch. Int. Med., 1913, 12, 153. 
24. Seltards, A. W. The Essential Features of Acidosis and Their Occurrence in Chronic Renal Disease. Bull. Johns Hopkins Hosp., 1914, 25, 141.

25. Sellards, A. W. A Clinical Method for Studying Titratable Alkalinity of the Blood and its Application to Acidosis. Bull. Johns Hopkins Hosp. 1914, 25, 101.

26. Howland, J. and Marriott, W. McK. Acetone Production in Infancy and Childhood. Am. Jour. Dis. Child., 1916, 12, 459 .

27. Peabody, F. W. Studies on Acidosis and Dyspnoea in Renal and Cardiac Disease. Arch. Int. Med., 1914, 14, 236.

28. Lewis, T., Rrffel, J. H., Wolf, C. G. L., Cotton, T., BarCROFT, J. Observations Relating to Dyspnoea in Cardiac and Renal Patients. Heart, 1913-14, 5, 45.

29. Straub, H. and Schlayer. Die Uramie eine Säurevergiftung? München. med. Wchnschr., 1912, 59', 569.

30. Porges, O. and Leimdörfer, A. Ueber die Kohlensäurespannung bei Nierenerkrankungen. Ztschr. f. klin. Med., 1913, 77, 464 .

31. Straub, H. Azidose des Blutes bei Uramie. München. med. Wchnschr., 1914, 612, 1499.

32. von $\mathbf{J}_{A K S C H}, \mathbf{R}$. Ueber die Alkalescenz des Blutes bei Krankheiten. Ztschr. f. klin. Med., 1888, 13, 350.

33. Naunyn, B. Der Diabetes Melitus. Zweite Auflage, IVien, 1906.

34. Emerson, Charles P. Clinical Diagnosis. Coma and Acidosis. 1906 , page 193.

35. Fischer, Martin H. Oedema and Nephritis. 1912. New York.

36. Howland, J. and Marriott, W. McK. Study of Acidosis Occurring in the Nutritional Disturbances of Infancy. Am. Soc. Advancement of Clinic. Invest., 1915, page 18. Ibid., Acidosis Occurring with Diarrhoea. Am. Jour. Dis. Child., 1916, 11, 309. Ibid., A Discussion of Acidosis, with Special Reference to that Occurring in Diseases of Children. Bull. Johns Hopkins Hosp., 1916, 27, 63.

37. Fridericia, L. S. and Olsen, Otto. Untersuchungen über die Kohlensäurespannung in der Alveolarluft der Lungen bei akut febrilen Krankheiten. Deutsch. Arch. f. klin. Med., 1912, 107, 236.

38. Barcroft, J. The Respiratory Function of the Blood. 1914, page 260. 
39. Steenbock, H., Netson, V. E., Hatr, E. B. Acidosis in Omnivora and Herbivora and its Relation to Protein Storage. Jour. Biol. Chem., 1914, 19, 399.

40. Cuile, Geonge W. The Origin and Nature of the Emotions. Alkalescence, Acidity, Anesthesia. A 'Theory of Anesthesia. 1915 , page 227.

41. Rogers, L. and Sironten, $\Lambda$. J. The Alkalinity of the Blood in Kala-Azar and Cholera and the Technique of its Estimation. Indian Jour. Med. Research, 1915, 2, 867.

42. Sellards, A. W. and Silaklee, A. O. Indications of Acid Intoxication in $\Lambda$ siatic Cholera. Philippine Jour. Sc., Sec. B, $1911,6,53$.

43. McLauginun, A. J. and Sellards, A. W. Effect of the Concentration of Solution in the Treatment of Collapse in Asiatic Cholera. Philippine Jour. Sc., Sec. B, 1910, 5, 391.

44. Wherry, W. B. Forchheimer's Therapeusis of Internal Diseases. 1914, Vol. 4, 839.

45. Busquet, H. and Pachon, V. Inhibition Cardiaque et Sels de Sodium en Injection Intravasculaire. Compt. rend. Soc. de biol., 1909, 66, 127.

46. Loeb, JAcques. On the Production and Suppression of Muscular Twitchings and Hypersensitiveness of the Skin by Electrolytes. Chicago Deceunial Publications, First Series, $1903,10,3$.

47. MacCalluin, W. G. and Voegtlin, Carl. On the Relation of Tetany to the Parathyroid Glands and to Calcium Metabolism. Jour. Exper. Med., 1909, 11, 118.

MacCallum, IV. G. and Vogel, K. M. Further Experimental Studies in Tetany. Ibid., 1913, 18, 618.

MacCallum, W. G., Lambert, R. A. and Vogel, K. M. The Removal of Calcium from the Blood by Dialysis in the Study of Tetany. Ibid., 1914, 20, 149.

Voegtuin, Carl and MacCallum, IV. G. On the Influence of Various Salts Upon Tetany Following Parathyroidectomy. Jour. Pharmacol. and Exper. Therap., 1910-11, 2, 421.

48. Fischer, Martin H. Further Remarks on the Treatment of Nephritis. Tr. Assn. Am. Phys., 1912, 27, 608.

49. Edsall, David L. A Preliminary Communication Concerning the Nature and Treatment of Recurrent Vomiting in Children. Am. Jour. Med. Sc. (New Series), 1903, 125, 629.

50. Marriotr, W. McK. and Howland, J. Phosphate Retention as a Factor in the Production of Acidosis in Nephritis. Arch. Int. Med., 1916, 18, 708. 
51. von Noorden, CArr and Mohr, L. The Acid Autointoxications, 1903. (a) Page 78, (b) pp. 76 and 77, (c) pp. 21 and $54,(d)$ p. 13.

52. Osborne, T. B., Mendel, L. B., Ferry, Edna L. Feeding Experiments With Isolated Food-Substances. Carnegie Institution of Washington, 1911, Pub. 156, Part II, page 80.

53. Magnus-Levy, A. On Diabetic Acidosis. Bull. Johns Hopkins Hosp., 1911, 22, 46.

54. Henderson, L. J. and Palmer, IV. W. On the Intensity of Urinary Acidity in Normal and Pathological Conditions. Jour. Biol. Chem., 1912-13, 13, 393.

55. von Noorden, CARL. Metablism and Practical Medicine. Vol. 3, page 604. Pathology of Metabolism. 1907.

56. McCollum, E. V. and Hoagland, D. R. Studies of the Endogenous Metabolism of the Pig as Modified by Various Factors. Jour. Biol. Chem., 1913, 16, 299.

57. Eppinger, Hans. Beitrag zur Lehre von der Säurevergiftung. Wien. klin. Wchnschr., 1906, 19, 111. (An excellent discussion of ammonia excretion in herbivora and carnivora.)

58. Folin, Отто. Eine neue Methode zur Bestimmung des Ammoniaks im Harn und andern thierischen Fliissigkeiten. Ztschr. f. physiol. Chem., 1902-03, 37, 161. Ibid. Note on the determination of ammonia in urine. Jour. Biol. Chem., $1910-11,8,497$.

Folin, O. and Macalduni, A.B. On the determination of ammonia in urine. Jour. Biol. Chem., 1912-13, 11, 523.

59. Shaffer, P. A. A Method for the Quantitative Determination of $\beta$-Oxybutyric Acid in Urine. Jour. Biol. Chem., 1908-09, $5,211$.

Shaffer, P. A. and Marriott, WV. McK. The Determination of Oxybutyric Acid. Jour. Biol. Chem., 1913-14, 16, 265.

60. Marriott, W. McK. The Determination of Acetone. Jour. Biol. Chem., 1913-14, 16, 281; Nephelometric Determination of Minute Quantities of Acetone, Ibid., 1913-14, 16, 289; The Determination of $\beta$-Oxybutyric Acid in Blood and Tissues Ibid., 1913-14, 16, 293.

61. Boothiby, W. M. and Peabody, F. W. A Comparison of Methods of Obtaining Alveolar Air. Arch. Int. Med., 1914, 13,497 .

62. Fridericia, L. S. En klinisk Metode til Bestemmelse af Kulsyrespaendingen i Lungeluften. Hospital Stidende, 1914, 57,585 . 
62a. Poulton, E. P. The Significance of Alveolar Carbon Dioxide Determinations in the Treatment and Prognosis of Diabetes. British Medieal Jour., 1915, 2, 393.

63. Howland, J. and Marmott, W. McK. Acidosis Occurring with Diarrhoea. Am. Jour. Dis. Child., 1916, 11, 309.

64. HaLdane, J. S. Methods of Air Aralysis. 1912.

65. Van Slyke, D. D. Communication to appear in the June number of the Jour. Biol. Chem., 1917, vol. 30.

66. Sörensen, S. P. I. Ueler die Messung und Bedeutung der Wasserstoffionenkonzentration bei biologischen Prozessen. Ergebnisse d. Physiol., 1912, 12, 393.

HasselbalciI, K. A. Elektrometrisclie Reaktionsbestimmung kohlensäurehaltiger Flüssigkciten. Biochem. Ztschr., 1911, $30,31 \%$.

Hasselbalcii, K. A. and Lundsgaard, Chr. Electrometrische Reaktionsbestimmung des Blutes bei Körpertemperatur. Biochem. Ztsehr., 1912, 38, 77.

Micitaelis, Leonor and Rona, Peter. Electrochemische Alkalinitätsmessungen an Blut und Serum. Biochem. Ztschr., $1909,18,317$.

66a. Michaelis, L. Die Wasserstoffionenkonzentration, ihre Bedeutung für die Biologie und die Methoden ihre Messung. Berlin, 1914.

67. Levy, R. L., Rowntree, L. G., Marriott, W. McK. A Simple Method for Determining Variations in the HydrogenIon Concentration of the Blood. Arch. Int. Med., 1915, 16, 389.

Levy, R. L. and Rowntree, L. G. A Study of the Buffer Value of the Blood. Arch. Int. Med., 1916, 17, 525.

68. Brandenburg, F. Cited by Emerson, Charles P., Clinical Diagnosis. 1913, 4th ed., page 569 .

69. Folin, Otтo. The Acidity of Urine. Am. Jour. Physiol., 1903, 9, 205.

70. Peters, J. P., Jr. Carbon dioxide Acidosis: The Cause of Cardiac Dyspnoea. Am. Jour. Physiol., 1917, 43, 113.

71. Josuin, E. P. The Treatment of Diabetes Mellitus. 1916, page 295. 


\section{INDEX OF AUTHORS}

Barcroft, J., 40, 50.

Benedict, H., 18.

Boothby, W. M., 96, 98.

Boussingault, M., 3.

Brandenburg, F., 106.

Busquet, H., 59.

Cammidge, P. J., 22.

Cotton, T., 40.

Crile, G. W., 51.

Cullen, G. E., 21.

Edsall, D. L., 67.

Emerson, C. P., 42.

Eppinger, H., 116.

Ferry, E. L., 68, 81.

Fischer, M. H., 44, 62, 63, 65, 80.

Folin, O., 3, 18, 95.

Fridericia, L. S., 49, 96.

Frothingham, C., 20, 49.

Gammeltoft, S. A., 19.

Haldane, J. S., 96.

Hallervorden, E., 3.

Hart, E. B., 51.

Hasselbalch, K. A., 19.

Henderson, I. J., 9, 10, 13, 26, 33, 74, 84, 108.

Hoagland, D. R., 80.

Howland, J., 35, 48, 66, 67, 75, 99.

Janney, N., 112.

Jones, H. C., 112.

Joslin, E. P., 66.

Kussmaul, A., 3.

Leimdörfer, A., 21, 40, 52.

Lewis, T., 40.

Loeb, J., 59.

MacCallum, W. G., 59 .

McCollum, E. V., 80.

McLaughlin, A. J., 58.

Magnus-Levy, A., 73.
Markovici, E., 21, 52.

Marriott, IW. McK., 21, 35, 48, 66, 67, $75,95,99,100$.

Mendel, L. B., 68, 81.

Michaelis, L., 19.

Naunyn, B., 42.

Nelson, V. E., 51.

Olsen, O., 49.

Osborne, T. B., 68, 81.

Pachon, V., 59.

Palmer, W. IV., 26, 33, 74, 108.

Peabody, F. IW., 19, 39, 68, 72, 74, $96,98$.

Peters, J. P., Jr., 52.

Porges, O., 21, 40, 52.

Poulton, E. P., 96.

Rogers, L., 57.

Rowntree, L. G., 20, 33, 106.

Ryffel, J. H., 40.

Schlayer, 40.

Sellards, A. W.. 113. 114, 115.

Shaffer, P. A., 95.

Shaklee, A. O., 58.

Shorten, A. J., 57.

Sörensen, S. P. L., 117.

Stadelmann, E., 3.

Steenbock, H., 51.

Stillman, E., 21.

Straub, H., 40.

Van Slyke, D. D., 20.

von Jaksch, R., 41.

von Noorden, C., 48, 53, 68.

Walker, I. C., 20, 49.

Walter, F., 3.

Wherry, W. B., 59.

Wilson, D. W., 14.

Wolf, C. G. L., 40. 


\section{INDEX OF SUBJECTS}

Acetone

acidosis persisting after disappearance of, 35 .

determination of, 95 .

interpretation of, 35.

occurrence of, 77.

"Acetone bodies," variability of, in acidosis, 77 .

"Acidaemia," 43.

Acidosis

choice of tests for, 38 .

clinical signs of, 17.

compensated and uncompensated, 43.

definition of, 47 .

early observations, 3 .

etiology, 73.

experimental production of, 3,67 .

fundamental and incidental features of, 76 .

laboratory methods for detection of, 17.

occurrence of, 48.

proof of, in early nephritis, 39.

" relative" and " absolute," 43.

relative value of various tests for, 34.

therapy of, 53 .

Acids, excess of, in normal diet, 9 .

Air hunger

explanation of, 13 .

noted by Kussmaul, 3 .

symptom of acidosis, 17.

Alkalies

choice of, for therapy, 65 .

depletion of, in nephritis, 63 .

essential to life, 4 .

precautions in use of, 65 . preparation of, for injection, 108.

symptoms following depletion of, 62.

treatmeut by, see therapy.

Alkalinity, titratable, see Titratable alkalinity.

Alkali starvation, 42.

Alkalosis, 14, 84.

lack of evidence for, 15, 16 .

Alveolar air

carbon dioxide of, 17.

determination of carbon dioxide in, 95.

interpretation of carbon dioxide of, 21.

lowering in nephritis of carbon dioxide of, 40.

Ammonia

discovery of pathological amounts of, 3 .

effect of alkali therapy on, 78 .

increase of, in primary disturbances of protein metabolism, 23.

normal amounts of, in certain forms of acidosis, $23,75,77$.

physiological occurrence of, in urine, 10.

relationship to other tests for acidosis, 37.

Asiatic cholera

tolerance of patients to bicarbonate, 25.

treatment of acidosis in, 54

Association, 5.

$\beta$-oxybutyric acid

discovery of in urine, 3 .

determination of, 95 .

Sie also "Acetone bodies." 
Bicarbonate

determination of tolerance to, 107 . execretion of, in health, 24 .

storage of, in acidosis, 25 . sterilization of, 108.

Blood

carbon dioxide of, 17.

carbon dioxide of, in uraemia, 32.

composition maintained at expense of other tissues, 46,88 .

determination of carbon dioxide of, $32,107$.

determination of titratable alkalinity of, 103.

physicochemial reaction of, 18 . reaction in pregnancy, 19.

Calcium, 22, 24, 67, 68, 82.

Carbon dioxide determination of, in blood, 107. determination of, in alveolar air, 95.

interdependency of, in blood and alveolar air, 20.

lowering of, in cardiac cases, 21 . lowering of, at high altitudes, 21 . lowering of, in uraemia, 32 .

relationship to other tests for acidosis, 35.

Cirrhosis of liver, acidosis in, 49.

\section{Comas}

differentiation of, 70 .

from lack of salts, 68 .

Compensatory processes, 12.

Definition of acidosis, 47, 83 .

Diabetes, use of alkalies in, 66, 89 .

Diagnosis of acidosis, 17.

Diet, excess of acids in normal, 9 .

Differentiation of comas, 69.

Equilibrium between acids and bases, 4.

Henderson's factor, 9 . mechanism of, in health, 11. mechanism of, in disease, 12, 84 .

Etiology

defective oxidation in diabetes, 73.

defective elimination in nephritis, $73,74,75$.

Exaggeration of frequency of acidosis, 51.

Excretion, faulty, as cause of acidosis, 74.

Experimental acidosis, 3, 67.

Fixed bases, necessary for internal respiration, 13.

" Food-intoxications," acidosis in. 48.

Fundamental features of acidosis, 76, 85.

Hepatic cirrhosis, acidosis in, 49 .

Historical note, 3 .

Hydrogen ion concentration, 7 . constancy of, 84.

maximal change of, in acidosis, 19.

Hydroxyl ion concentration, 7.

Indicators, 6 .

Internal Respiration, rôle of fixed bases, 13.

Interpretation of

acetone, 35 .

ammonia, 37.

carbon dioxide, 21.

tolerance to bicarbonate, 26,33 .

Laboratory tests for acidosis, 17 effect of therapy on, 64 .

Law regarding composition of blood in disease, 46,88 .

Magnesium, 22, 24, 68.

Nephritis

acidosis in earlier stages, 39 .

as a cause of acidosis, 80 .

carbon dioxide of alveolar air in, $\mathbf{4 0 .}$ explanation of acidosis in, 74 .

in Asiatic cholera, 25.

treatment of acidosis in, 60 .

Neutrality Regulation. See equilibrium between acids and bases

Occurrence of acidosis, 48. 
Oedema, 63.

Parathyroid tetany, 14.

Phosphates

increased in acidosis, 75.

in neutrality regulation, 9 .

Physicochemical reaction, 6 . of blood in acidosis, 18. principle of method for determining, 105.

Pregnancy, reaction of blood in 19.

Qualitative changes, absence of, in compensation against acidosis, 83.

Quantitative changes of normal compensatory processes, 12 .

Reaction

" titratable," 5.

physicochemical, 6 .

to indicators, 6 .

and titration values, 7 .

Relationship of various tests for acidosis, 34.

Résumé, 81.

Sterilization of Bicarbonate, 108.

Symptoms of acidosis, 17 .

effect of alkali therapy on, 55,60 , 67.

of depletion of alkali, 61,87 .

Tables

effect of treatment on titratable al. kalinity, 31.

fundamental and variable features of acidosis, 77 .

physicochemical reaction and titration values, 7 .
Therapy of Acidosis

choice of alkali for, 65.

effect of, on laboratory tests, 64 .

in Asiatic Cholera, 5.

in food " intoxications," 66.

in nephritis, 60 .

sterilization of bicarbonate for, 108 .

theory of, 53.

Titratable alkalinity of blood determination of, 103.

relationship to other tests for acidosis, 36.

Titratable reaction, 5,6 .

Tolerance to bicarbonate

delicacy of, as test for acidosis, 25.

determination of, 107 .

in Asiatic cholera, 25.

in nephropathies, 26.

in uraemia, 31.

interpretation of, $\mathbf{2 6}, 33$.

terminology, 33.

relationship to other tests for acidosis, 37 .

relationship to clinical symptoms, 61.

relationship to phenolsulphonephthalein tests, 69 .

Uraemia

carbon dioxide of blood in, 28.

titratable alkalinity of blood in, 31 .

Urine

original reaction of ammoniacal, 110.

total acidity, 22 .

Value relative of various tests for acidosis, 34 . 
PRINTED AT

THE HARVARD UNIVERSITY PBESS

CAMBRIDGe, MASS., U.S. A. 


\section{-}




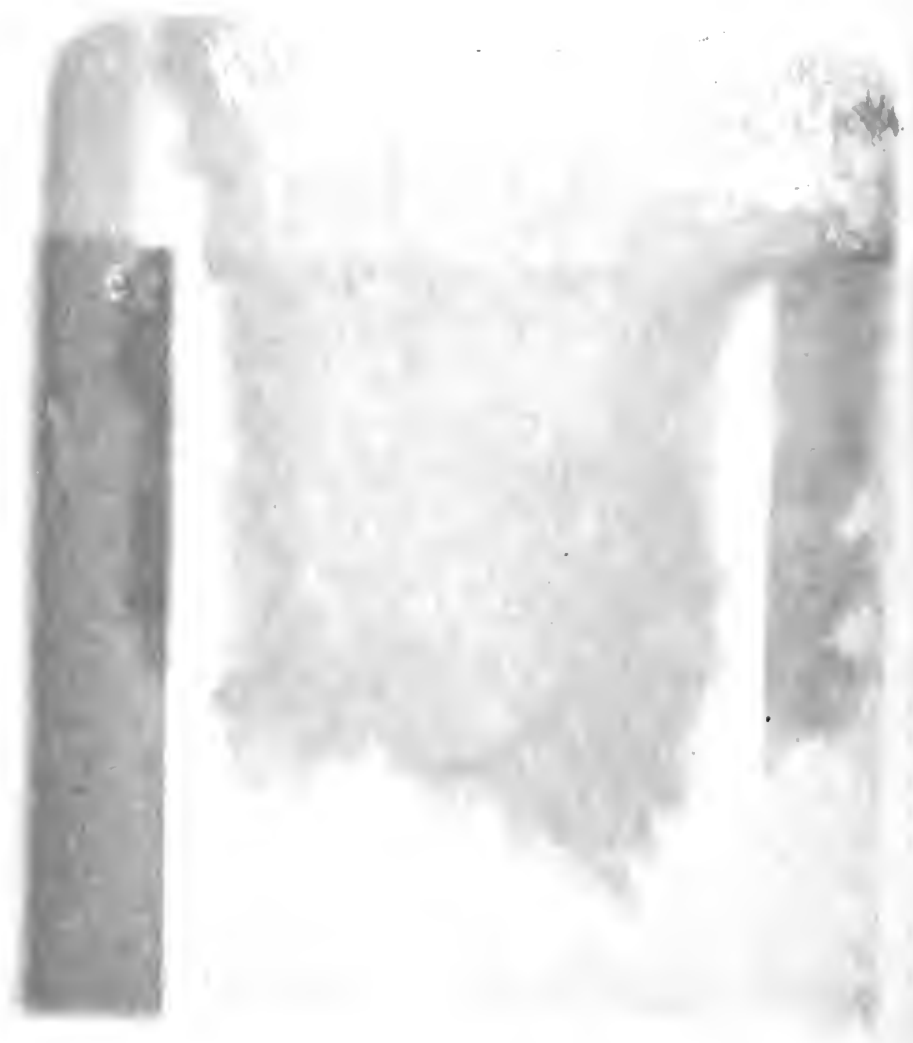




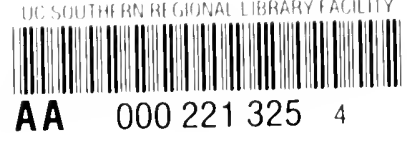


\% $3+3$

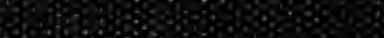

